This article has been scanned by iThenticat No plagiarism detected

Volume 3, Issue 5, October 2021

p. 294-305

\title{
EMOTION AND EMOTIONAL INTELLIGENCE: FROM CONCEPT AND MODELS TO MEASUREMENT AND APPLICATION
}

http://dx.doi.org/10.47832/2757-5403.5-3.26

\section{Abdelmounim KIOUACH ${ }^{1}$ \& Benaissa ZARHBOUCH²}

\begin{abstract}
:
This article approaches the emotional aspect of man, by focusing on emotional intelligence and the concepts associated with it according to two levels: Firstly; Invoking some theoretical models of emotional intelligence, as well as the most important models that explain it, with defining its dimensions. Secondly; See the scales used to measure it and its importance in psychological and social balance. It also aims to evoke the neural basis of this intelligence and its mental and nervous processes, and to monitor its relationship with the environment and genetics and its influence on them, to explain the differences between individuals. It has been shown that emotional intelligence plays a major role on the level of individual adaptation in different contexts: socially, scientifically, and academically. Because it is multifaceted, theoretical models have been crystallized for it; It may be cognitive, or models for a group of traits, or mixed models, which helped to build the standards currently known. By measuring emotional intelligence, it is possible to predict the individual's success or failure in social life, and may exceed mental intelligence in this.
\end{abstract}

Key words: Intelligence; Emotional Intelligence; Emotion, Affect; Emotional Intelligence Measures.

\footnotetext{
${ }^{1}$ Researcher, Sidi Mohamed Ben Abdellah University, Fez, Morocco, kmounim@yahoo.fr, https://orcid.org/0000-0003-4075-7203

${ }^{2}$ Prof.Dr. , Department of Social Sciences, Qatar University, z-benaissa@hotmail.fr. https://orcid.org/0000$\underline{0002-2388-2283}$
}

Copyright (C) Published by IJHER Journal, www.ijherjournal.com Rimar Academy, Fatih, Istanbul, 34093 Turkey

All rights reserved 


\title{
الوجدان والأكاء الوجداني: من المفهوم والنماذج إلى القياس والتطبيق
}

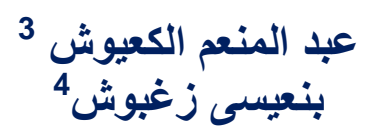

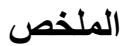

يقارب هذا المقال الجانب الوجداني لدى الإنسان، من خلال التركيز على الذكاء الوجداني

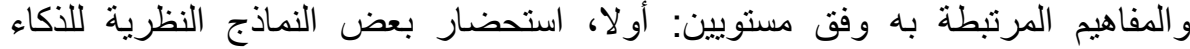

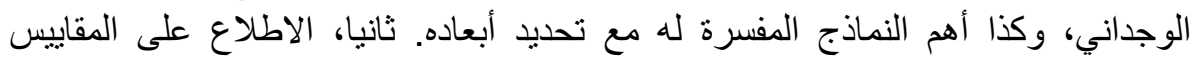

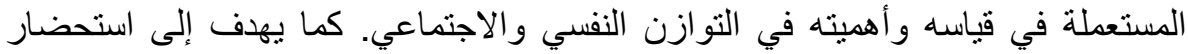

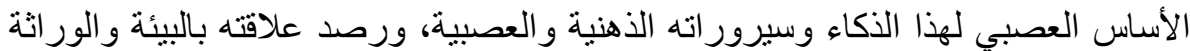

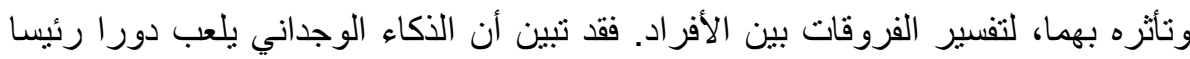

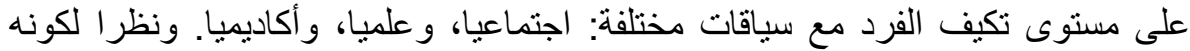

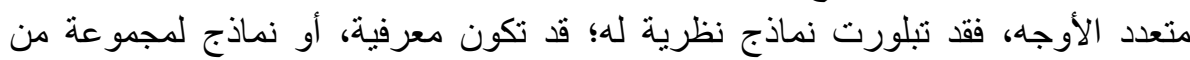

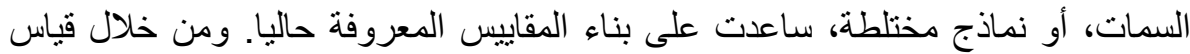
الذكاء الوجداني، يمكن التنبؤ بنجاح الفرد أو فثله في الحياة الاجتماعية، وقد يتجاوز الذياء العقلي في ذللك. الكلمات المفتاحية: الذكاء؛ الذكاء الوجداني؛ الانفعال، الوجدان؛ مقاييس الذكاء الوجداني.
\end{abstract}

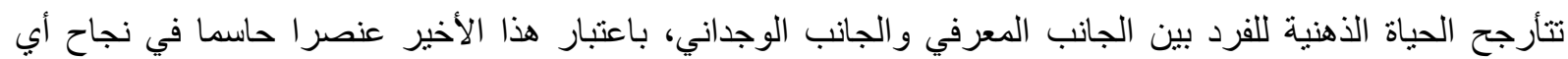

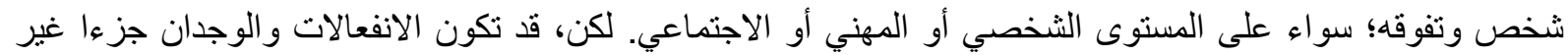

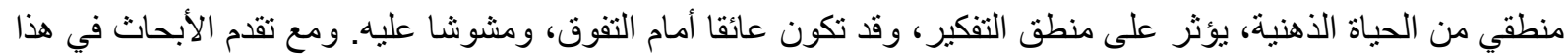

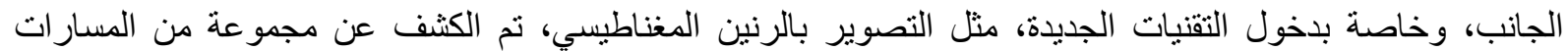

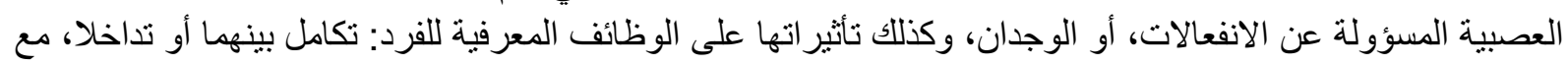

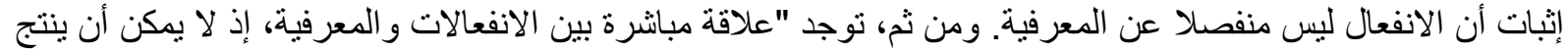

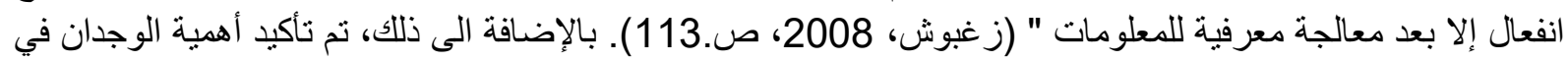

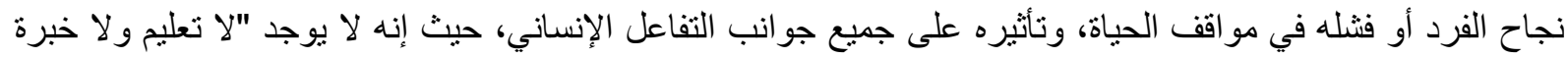

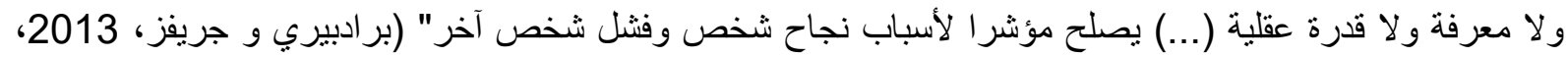

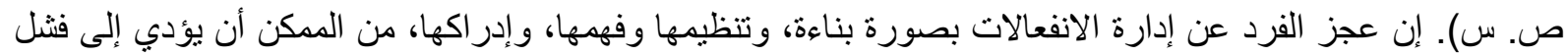

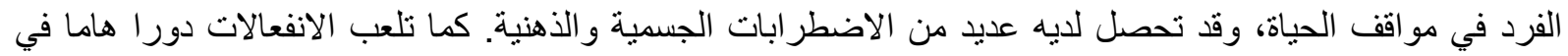

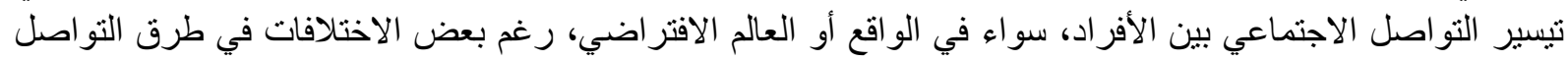
بين هاتين البيئتنين.

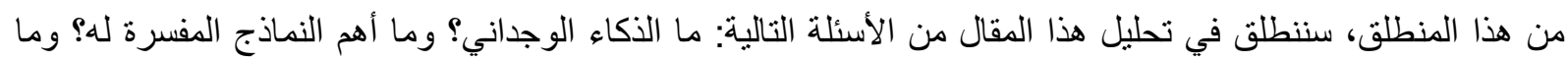

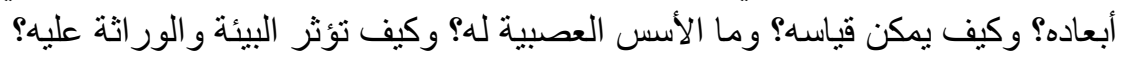

2. - 2 التمايز المفاهيمي للجانب الانفعالي للإنسان

نلاحظ اختلافات في الترجمة العربية عند نقل مصطلح Emotion للعربية، وكذلك الاستعمالات المتداولة بالتناوب لكل

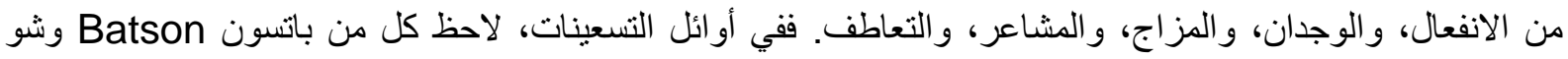

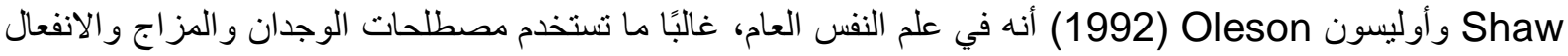


التناوب، دون أي محاولة للتمايز المفاهيمي بينها (Ekkekakis, 2012)، وهو الأمر الذي يستدعي مناقشة هذه المصطلحات لضبط مضامينها.

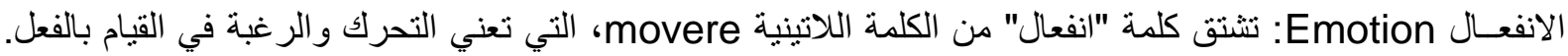

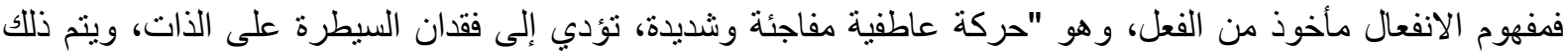

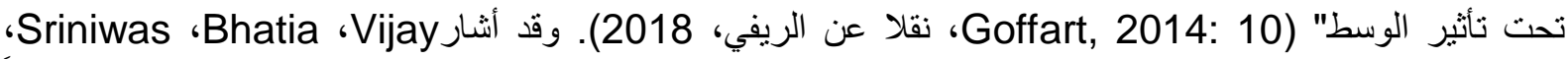
و Batra (2011) إلى أن الانفعال عبارة عن حالة مثيرة وفجائية، بسبب التغيرات الفسيولوجية التي تحدث، استجابةً

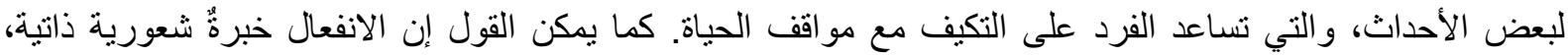

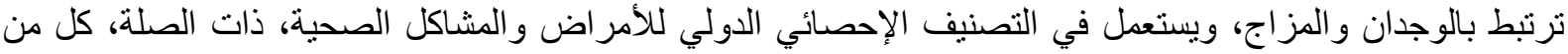

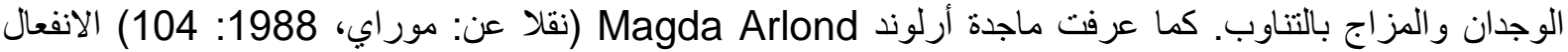

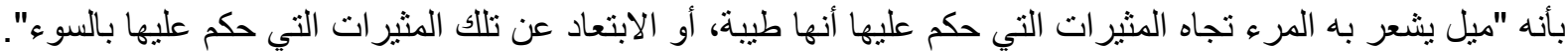
ويفترض روبرت بلوتشيك Robert Plutchik (نقلا عن: موراي، 1988) صاحب نظرية حول المزيج الانفعالي،

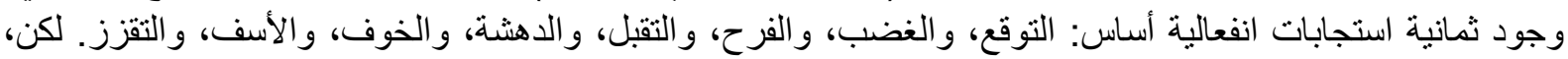
في منتصف القرن العشرين، اقترح الباحثون في علم النفس (راجع: Briner \& Totterdell, 2002 ستة انفعالات

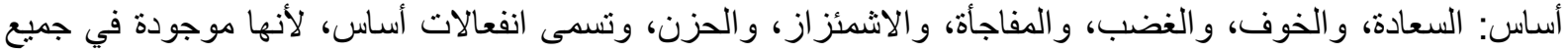

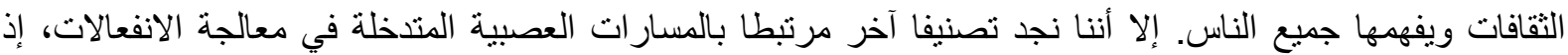

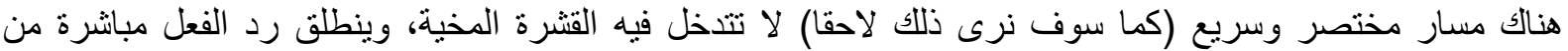

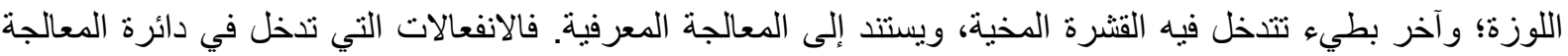

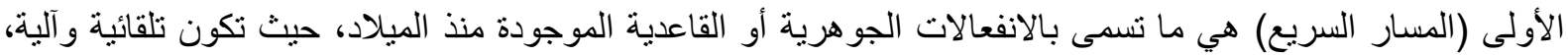

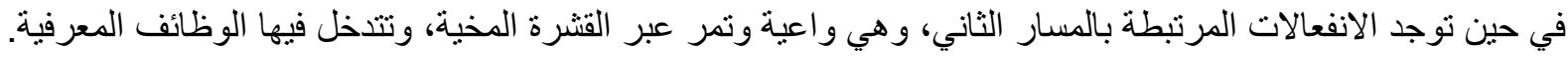

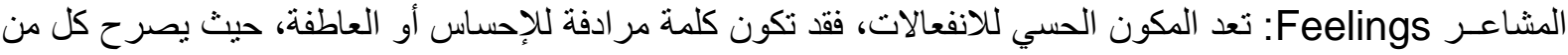

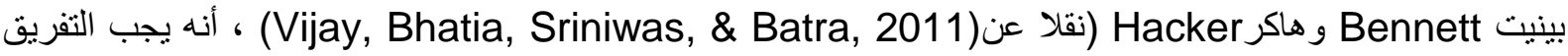

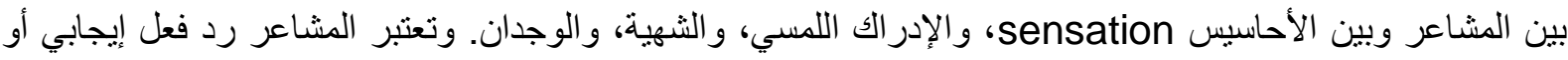

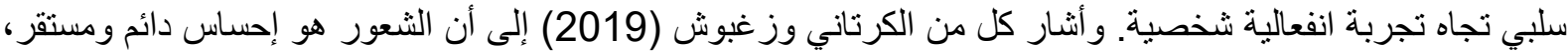

و إدراك بإحدى الحواس الظاهرة أو الباطنة. التعاطف Empathy: يعتبر أحد المكونات الرئيسة للذكاء الوجداني (loannidou \& Konstantikaki, 2008)،

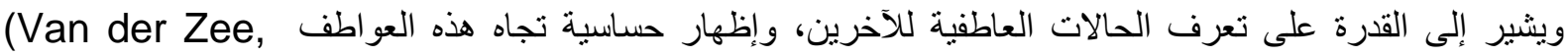

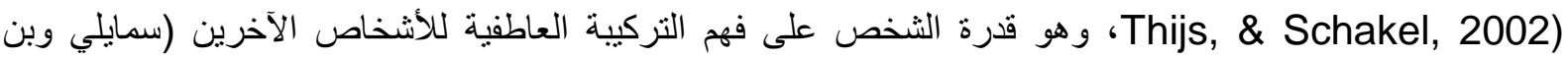

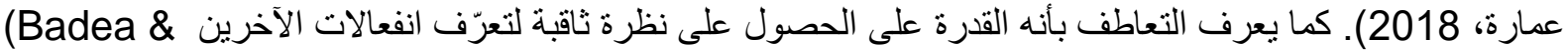

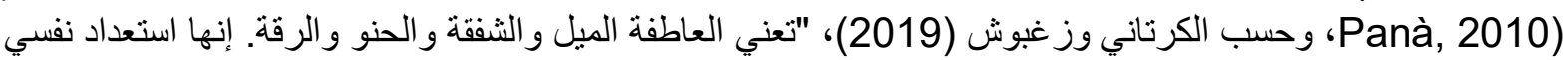
ينزع بصاحبه إلى الثتعور بانفعالات وجدانية خاصة، والقيام بسلوك معين حيال شخص أو أو جماعة أو فكرة معينة (...)،

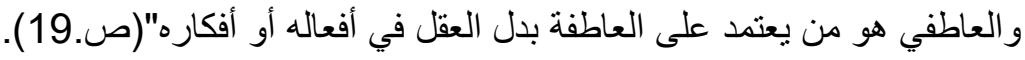

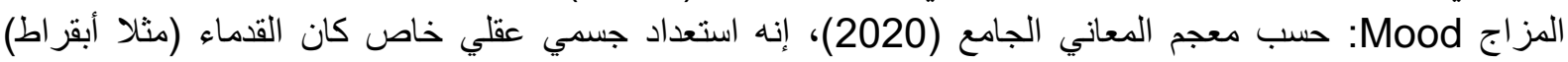

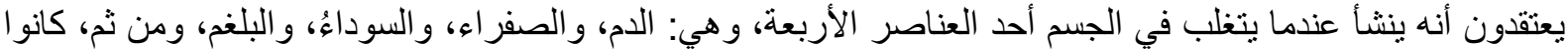

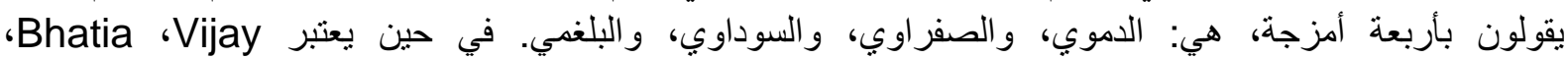
Sriniwas، وندatra (2011)، المزاج حالة انفعالية نستمر في الزمن لوقت أطول من الانفعال. وتعتبر الحالة

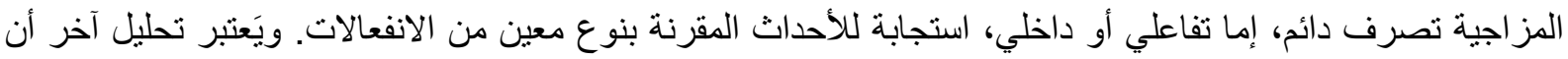

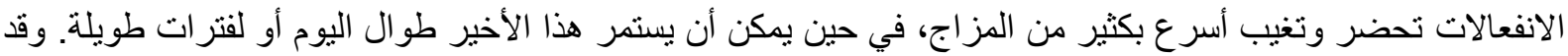

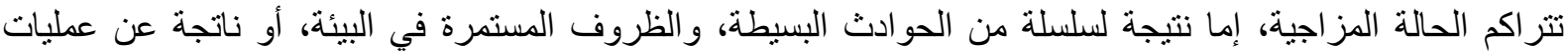

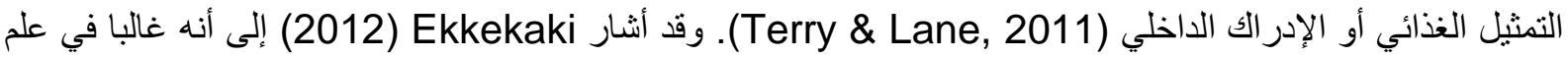

النفس العام، تستخدم مصطلحات: الوجدان، و المز اج، و الانفعال بالتبادل، دون أي محاولة تصورية للتفاضل بينها.

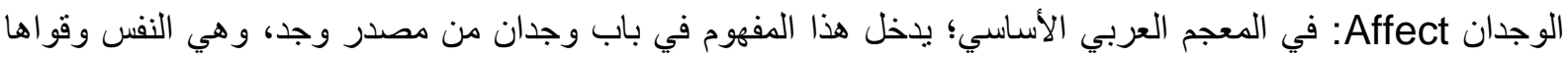

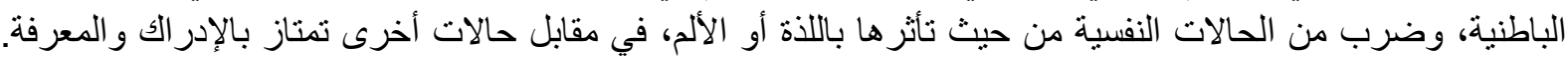

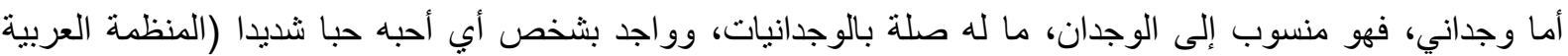

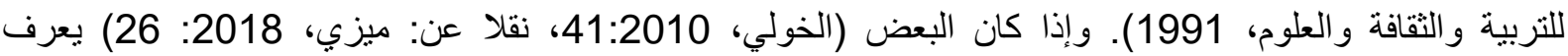


"الوجدان كاستجابة عقلية منظمة لحدث ما، لها مظهر فيزيولوجي، وسلوكي، ومعرفي"، فإن البعض اعتبر الوجدان حالة

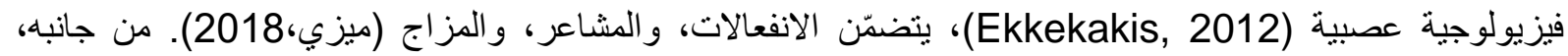

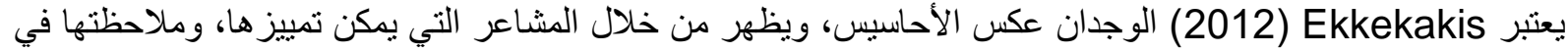

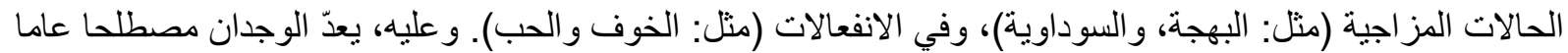

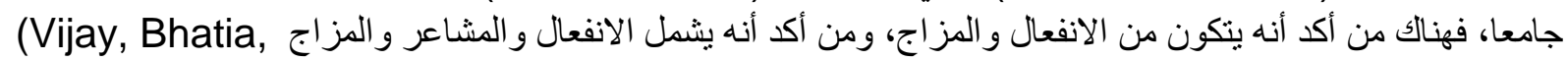
هإ. Sriniwas, \& Batra, 2011) هذا المصطلح في مقاربة الجانب الوجداني للإنسان.

3. نماذج الأكاء الوجداني

في إطار محاولة الباحثين فهم الذكاء الوجداني وقياسه، وتفسير هذا المكون الانفعالي لدى الإنسان، ظهرت ثلاثثة نماذج في

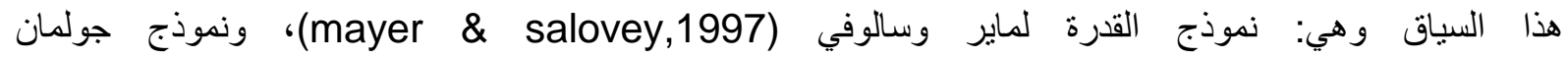

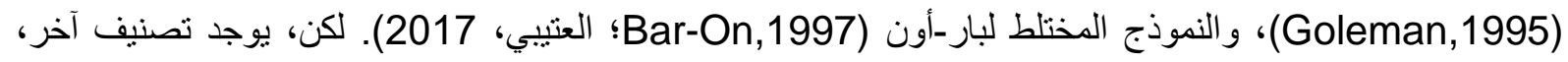
حسب فيوري Fiori وميلفير Maillefer (2018)، يؤكد، من الناحية المفاهيمية، على نموذجين سائدين ومختلفين لدراسة

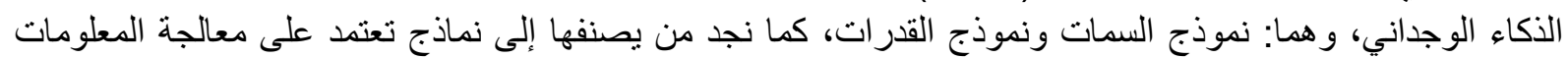
الوجدانية، ونماذج تستند إلى متغيرات الثخصية والسيمات السلوكية المستقرة (الغوداني، 2019). ونلاحظ أيضا من

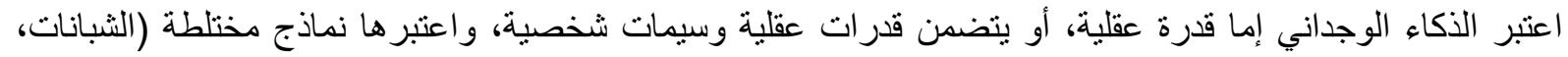

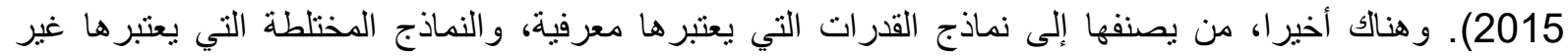

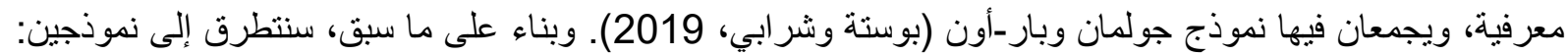
نموذج الذكاء الوجداني باعتباره قدرة عقلية أو سمة شخصية يدرجها أغلب الباحثين في النموذج المختلط (سمايلي وبن عمارة، 2018).

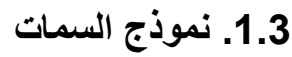

أنشارت فيوري وميلفير (2018) إلى أن نموذج السمات يعتبر الذكاء الوجداني ميو لات تصريفية، مثل سمات الثخصية

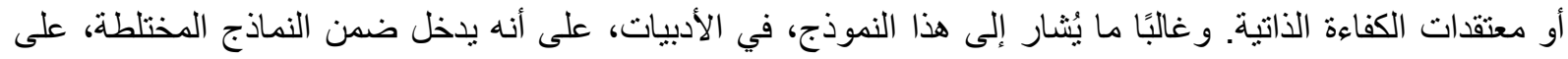

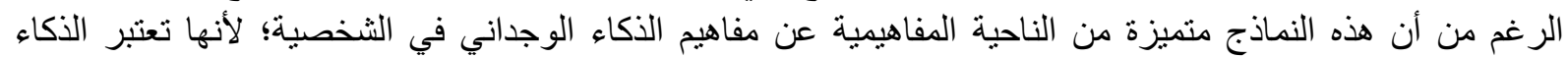

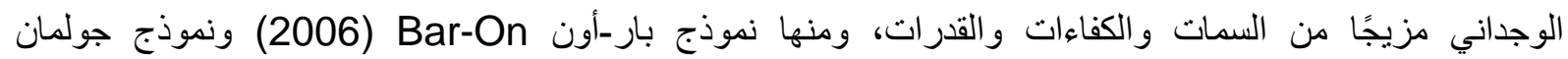

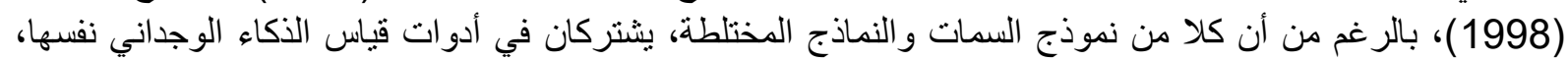

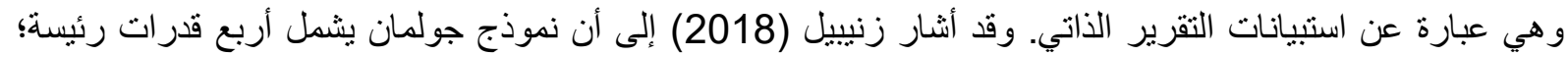

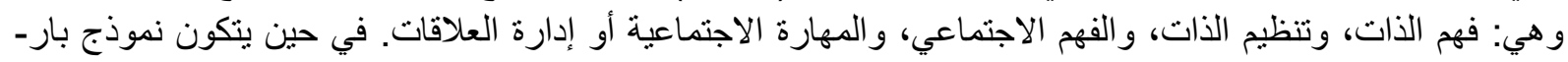

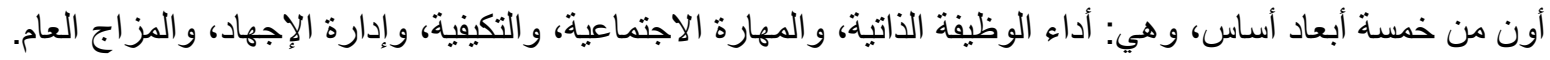

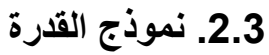

ينظر نموذج القدرة إلى الذكاء الوجداني باعتباره قدرة معرفية، لأنه بتأسس على معالجة المعلومات الانفعالية وتقييمها

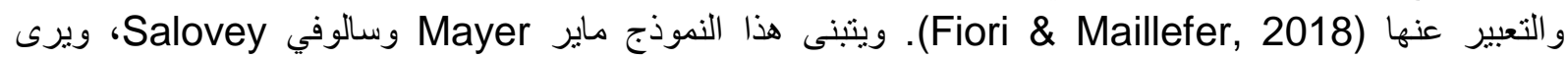

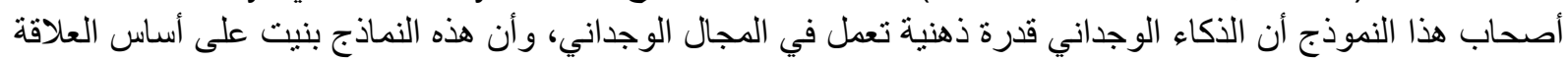

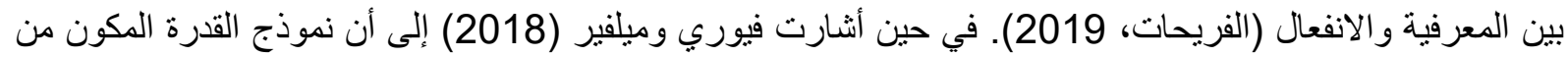

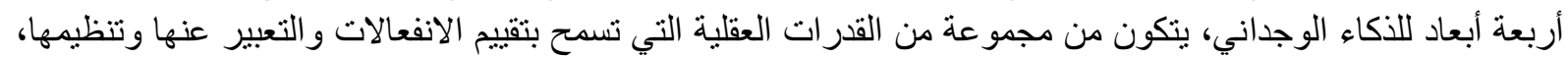

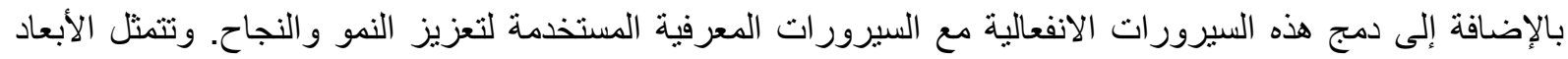

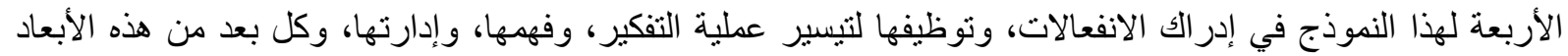

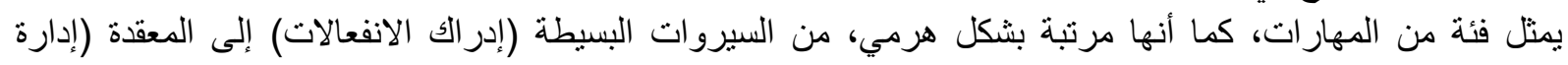

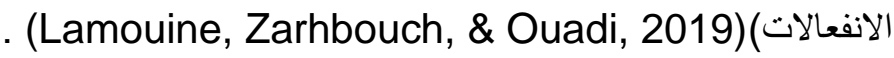


أشارت فيوري وميليفر (2018) إلى أن الذكاء الوجداني باعتباره قدرة، مثله مثل الذكاء العقلي، ينقسم بدوره إلى قسمين:

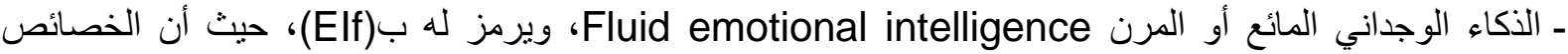
الور اثية للذكاء الوجداني تتجسد من خلاله، وهو مرتبط بقدرة معالجة المعلومات الانفعالية، ويكون بطريقة لاو اعية.

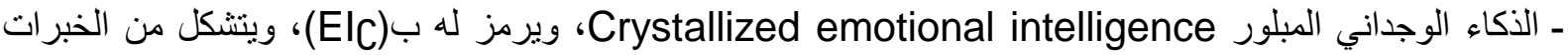

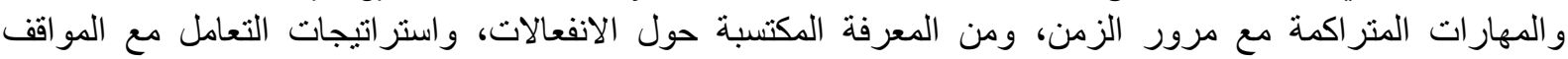
الانفعالية، وقد يعتمد الأفر اد على المعرفة التي يمتلكونها عن كيفية التعبير عن الوجدان لتحديد الانفعالات بشكل صحيح. ويتأسس هذا المكون بشكل أقوى على المعرفة المكتسبة والمرتبطة بالثقافة حول الانفعالات، وتتم هذه المنان المعرفة بطريقة

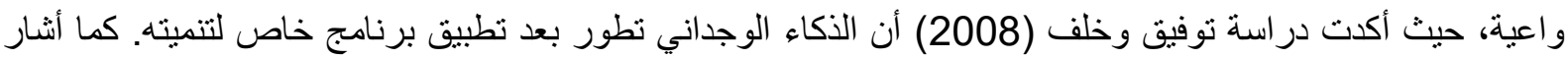
الثبانات (2015) إلى أن التحصيل الدر اسي يساهم في رفع مستوى درجة الذئاء التواء الوجداني و أبعاده.

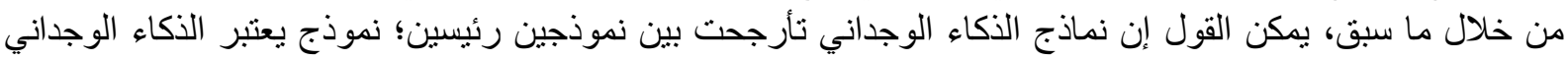

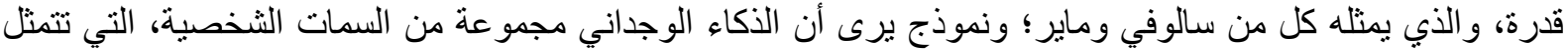

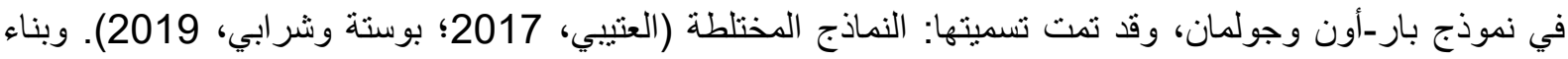

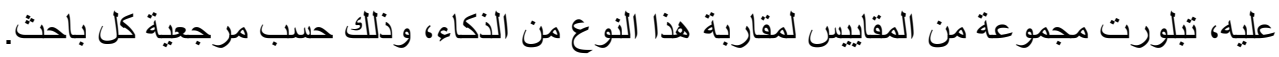

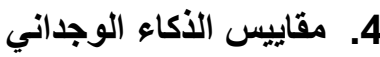

بتعدد التعاريف و النماذج المؤطرة للذكاء الوجداني، تعددت أيضا المقاييس التي تقيس هذا النوع من الذكاء، "حيث عمد كل

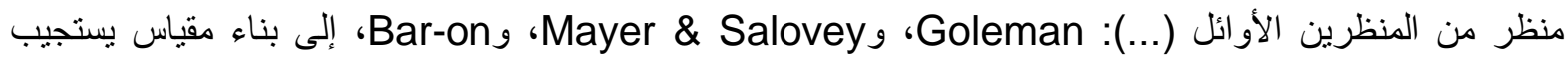

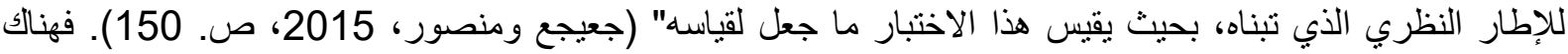

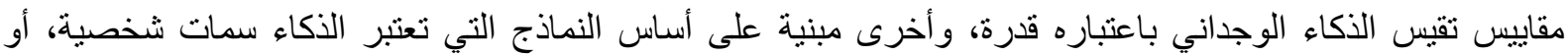

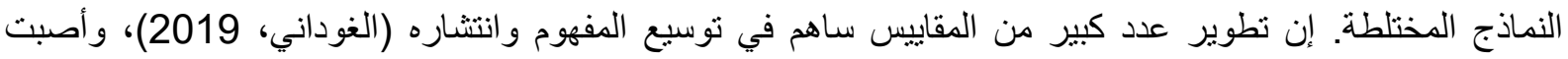
دراسته تتطرق إلى جميع الجوانب المرتبطة بهذا النوع من الذكاء، وهذا الأمر يعطي صورة ولفي واضحة وشمولية عن المفهوم.

1.4. مقاييس تقيس الذكاء الوجداني باعتباره قرة

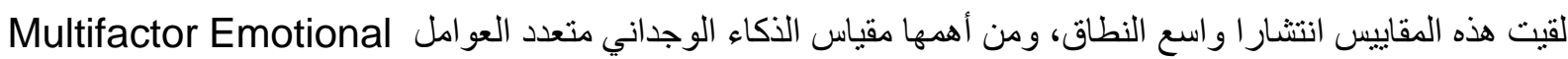
وسائ Intelligence Scale (MEIS) Mayer, Salovey, Caruso, Emotional Intelligence Test وسالوفي وكارسو للأكاء الوجدانية الانعالئ)، ويعتبر هذا المقياس أحدث من المقياس السابق، حيث يقيس قدرة الفرد على إنجاز المهمة وحل المشكلات

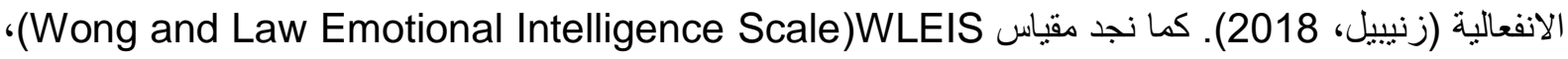

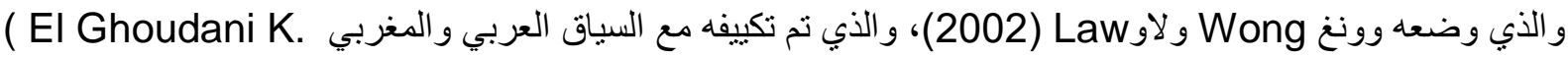
(2021) ، Ramos-Álvarez, LopezZafra, \& Pulido-Martos, 2021) ويعتبر أداة قصيرة، نتكون من 16 بندا، تقيس أربعة أبعاد (انظر أيضا: الغوداني، بوليدو-مارتوس ، لوبيز-ز افرا ، 2018؛ الغوداني، 2019).

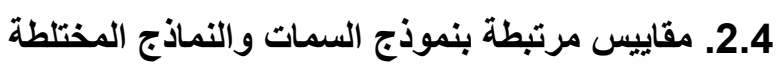

بالنسبة للمقاييس التي نشأت على أساس أن الذكاء الوجداني هو خليط من السمات الثخصبة و القدرات العقلية والمهارات الاجتماعية، نجد من أهمها مقياس معامل الذكاء الوجداني لبار -أون Bar-On Emotional Quotient- Inventory ونهar-On EQ-i)

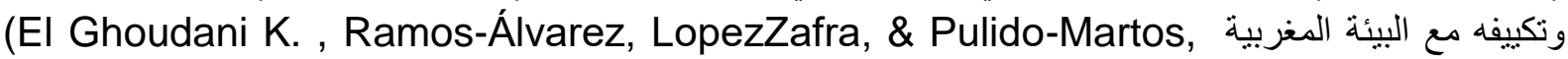

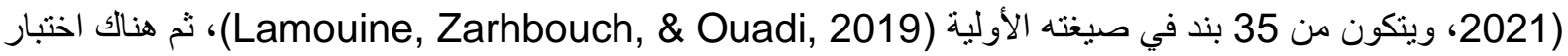
جولمان الذي أعده بناء على نموذج جولمان المختلط (زنيبيل، 2018). 


$$
\text { 5. 5 - 5 الأسس العصبية للأكاء الوجداني }
$$

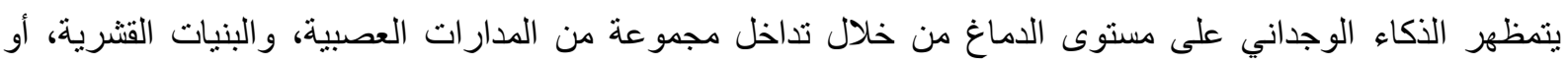

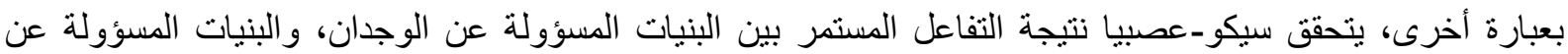

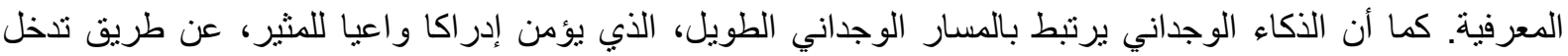

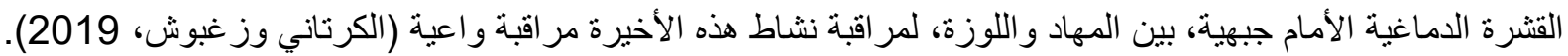

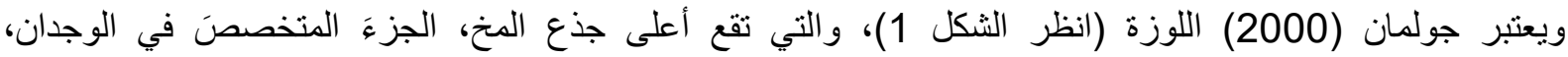

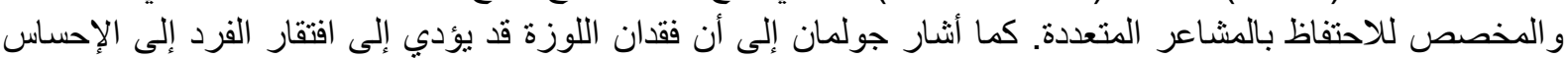
بالخوف أو الغضب، كما يفقد حاجز التنافس أو التعاون.

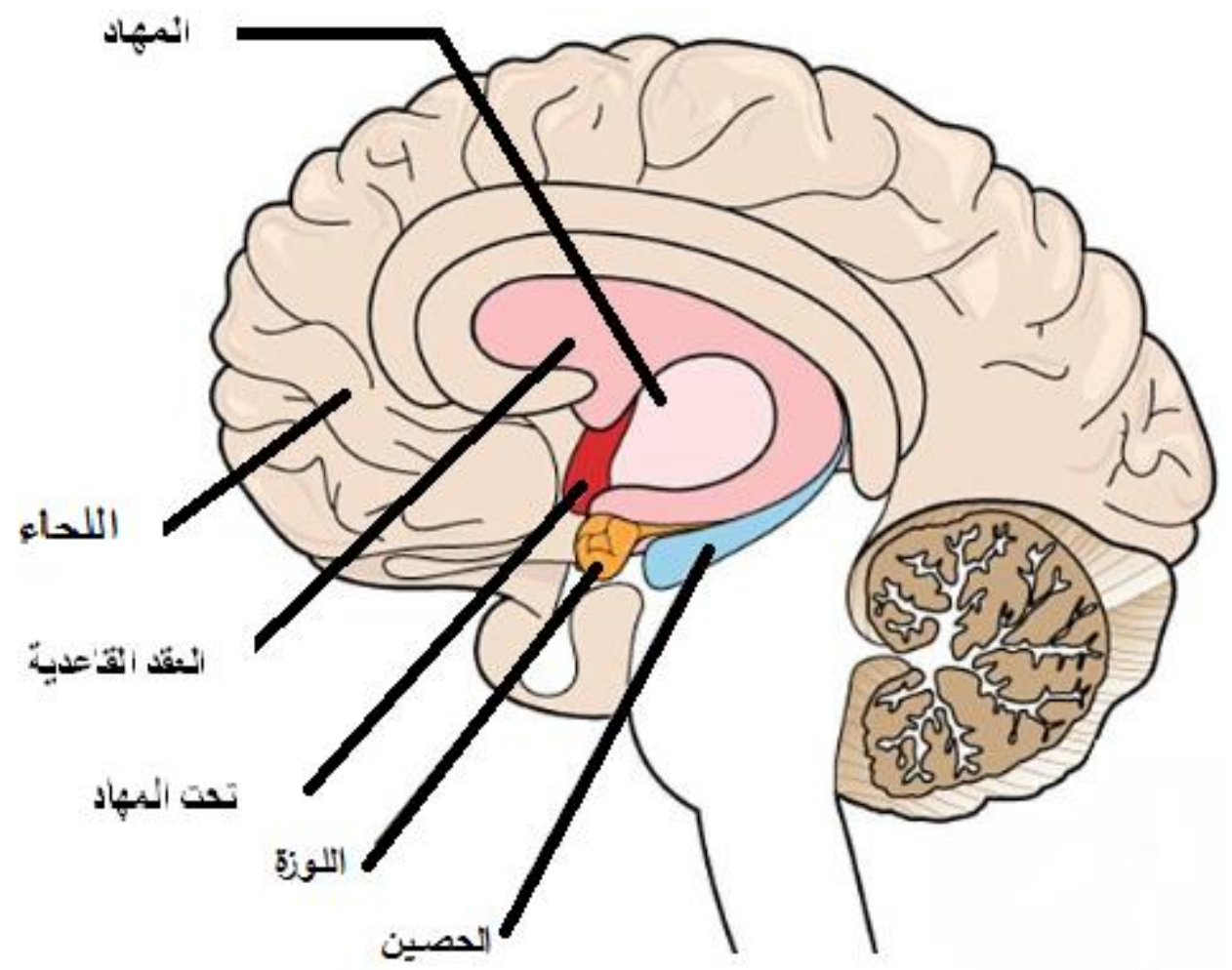

الثكل 1: صورة للوزة وبعض المناطق المجاورة المتدخلة في الوجدان (نقلا عن: شفقنا، 2020، بتصرف)

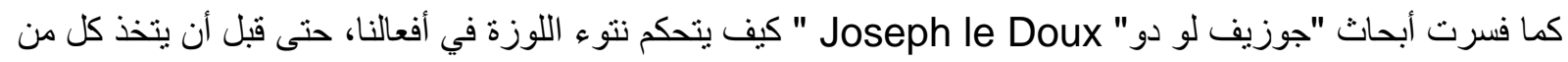

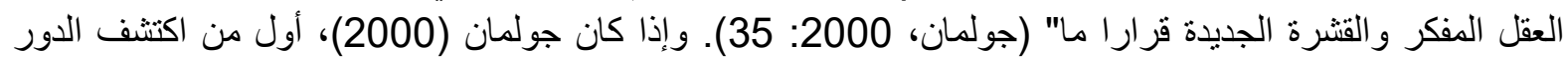

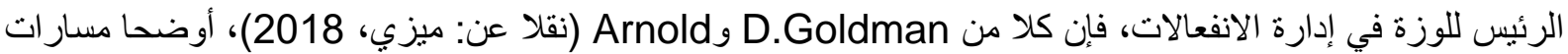

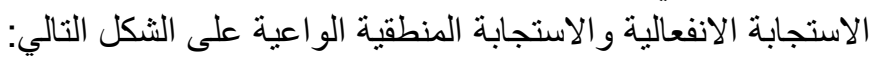




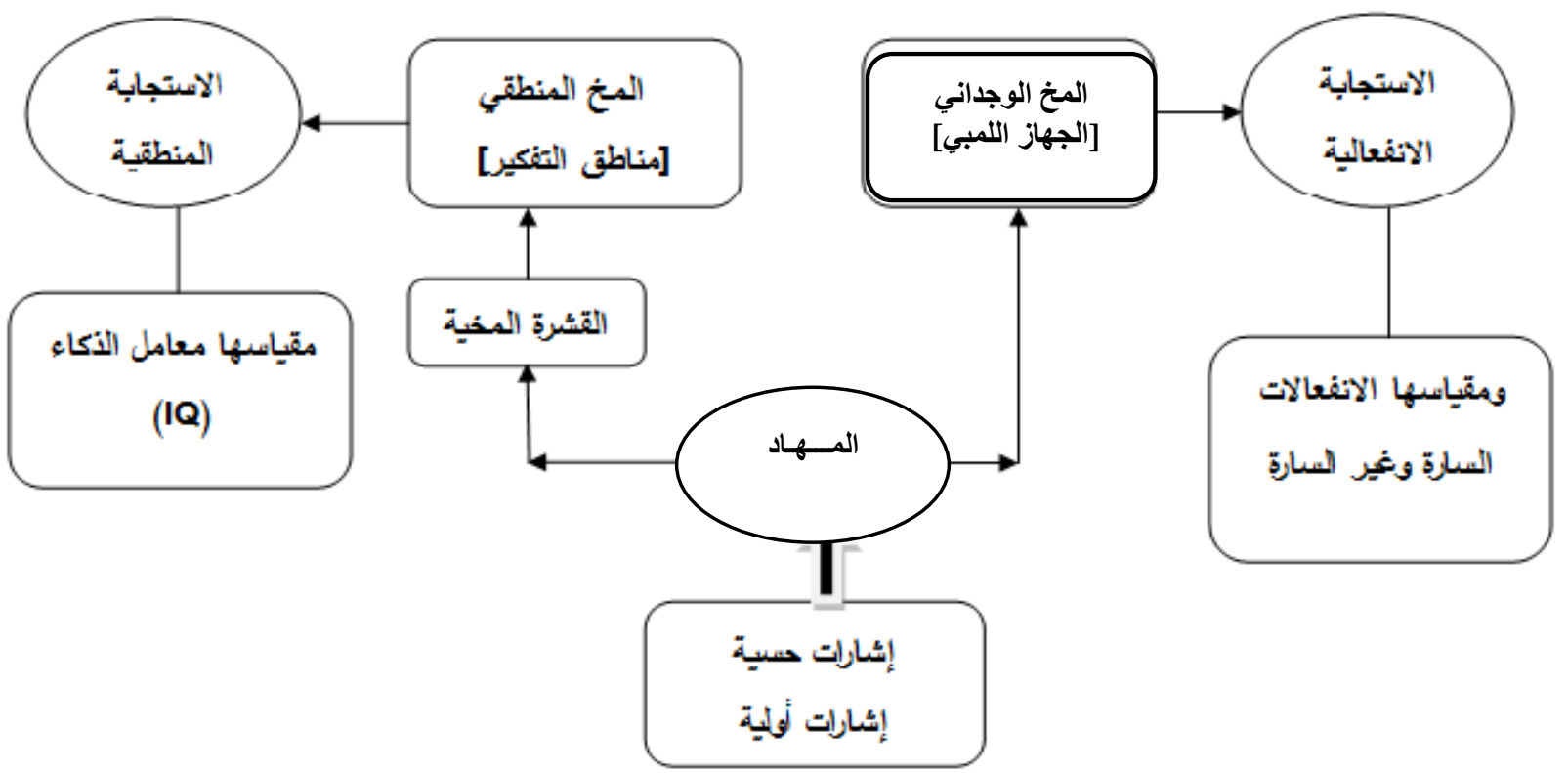

الثكل 2: الأساس الوظيفي للانفعالات بين المخ الوجداني والمخ المنطقي لGoldman و Arnold (نقلا عن: ميزي، 2018،

كما أن اللوزة تعمل على معالجة سريعة للإشارات الحسية القادمة من الحواس، لتنشيط الخلايا العصبية داخلها، والقيام

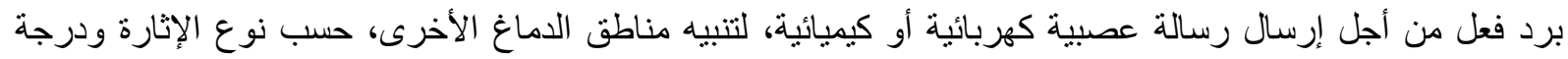

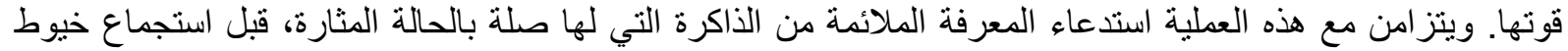

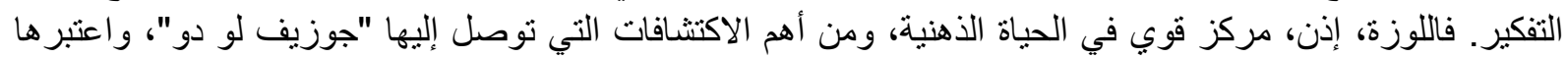

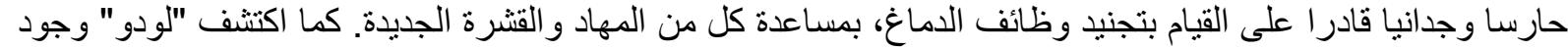

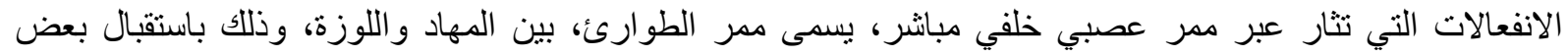

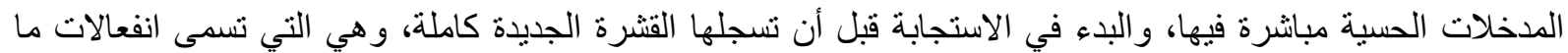

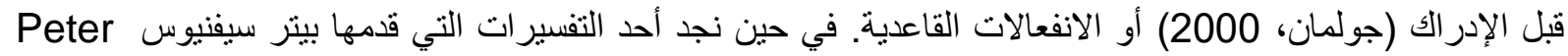

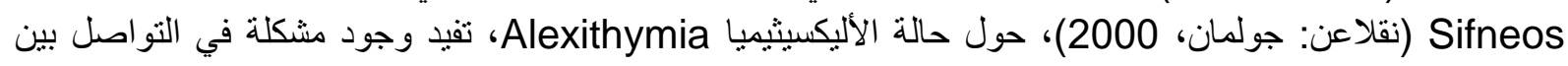

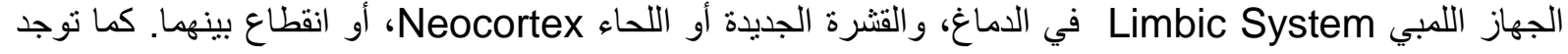

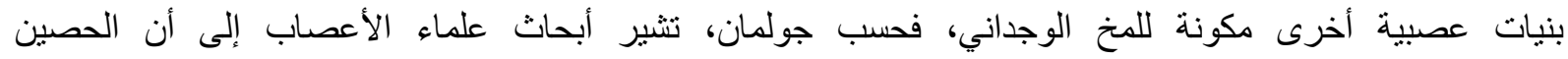
بعippocampus

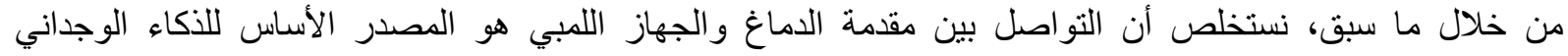

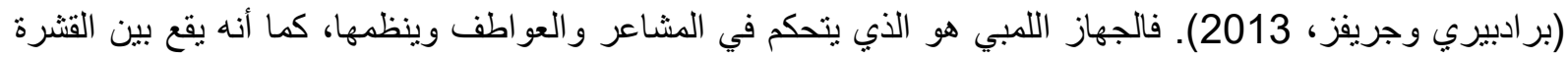
المخية وجذع الدماغ، وفي وسطه خلف العينين، نوجد اللوزة التي ترتبط مع الفص الأمامي بالوصلات العصبية (شنان

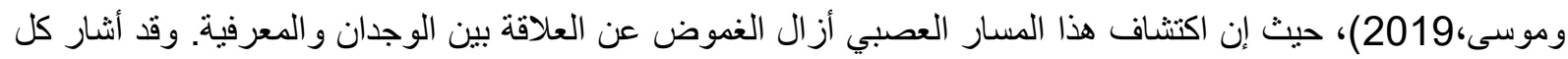

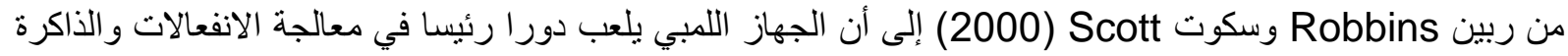

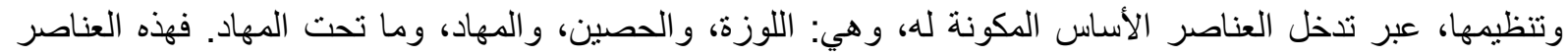

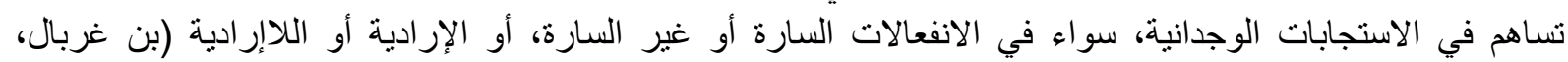

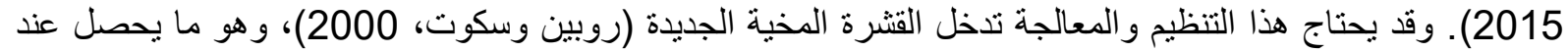
التفسير العصبي للذكاء الوجداني. فهل يتبلور الوجدان نتيجة لتدخل عوامل بيئيةٌ أم يكون نتيجة لبرمجة ولئ ور اثية؟

6. تأثير البيئة والوراثة على الذكاء الوجداني

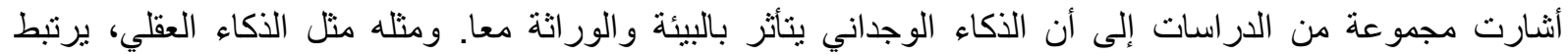

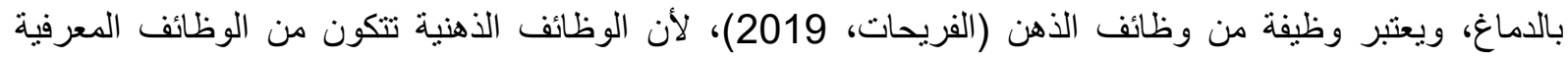

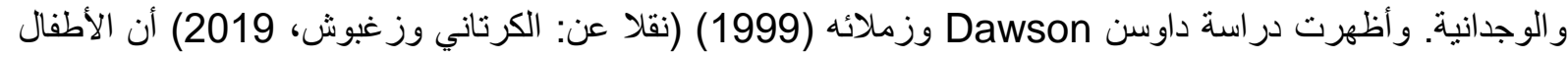

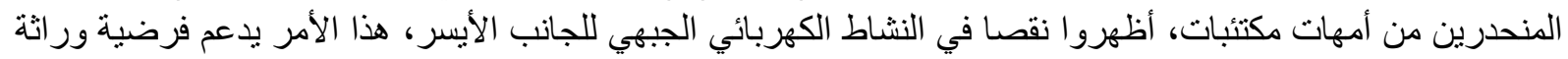




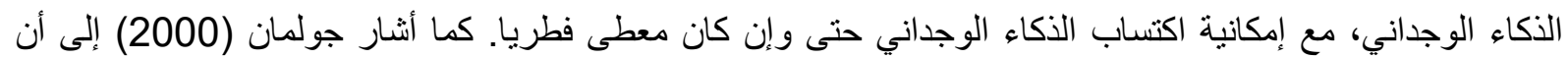

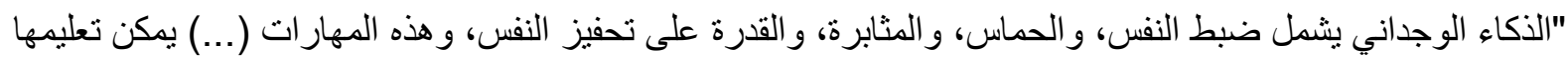

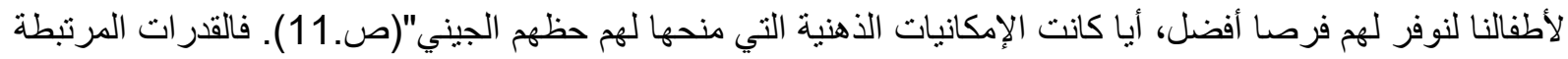

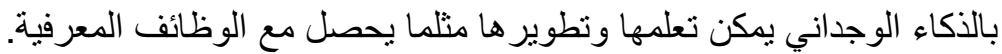

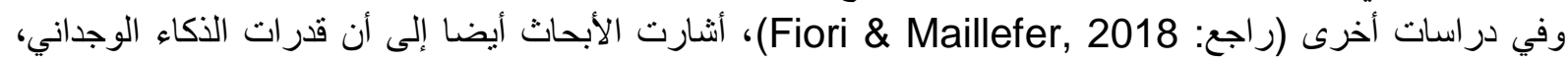

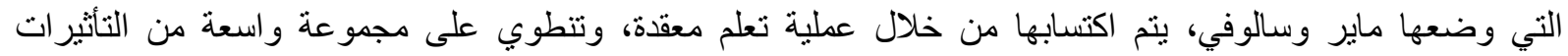

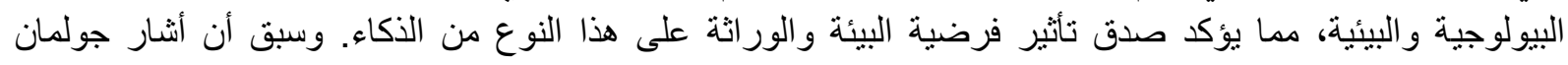

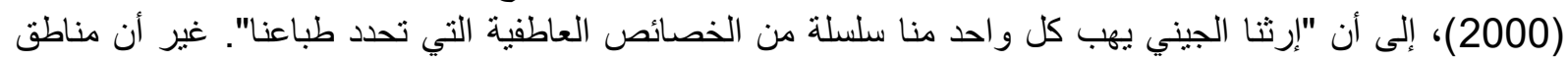

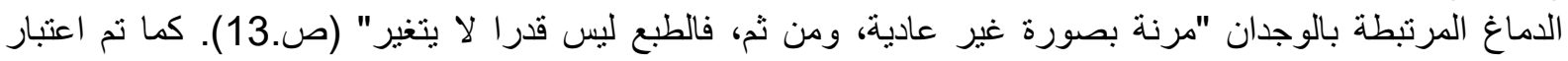

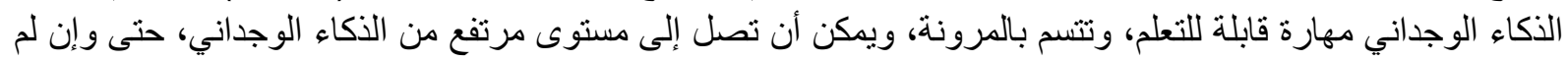

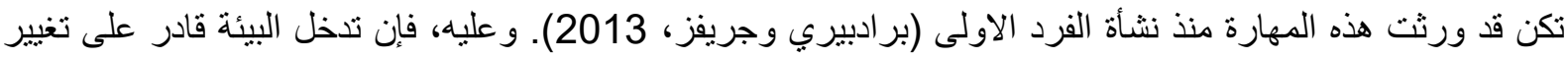

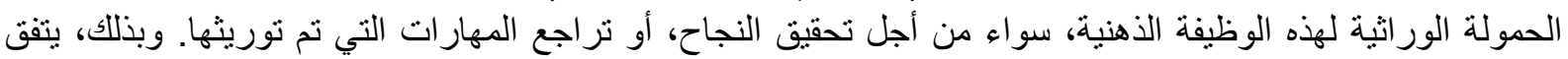

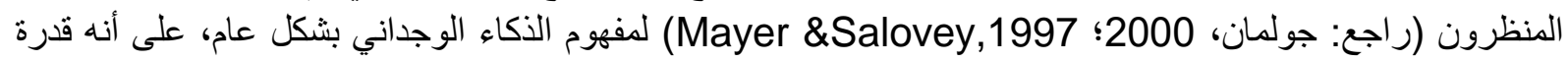

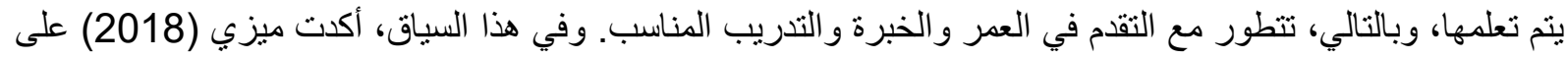

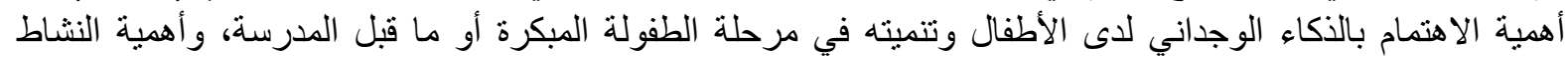

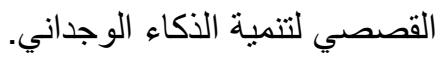
نخلص، مما سبق، أن الذكاء الوجداني ليس قدرا محتوما، وإنما بإن بإمكان أي فرد اكتساب قدر اته وسيماته الأساس، وتعلمها

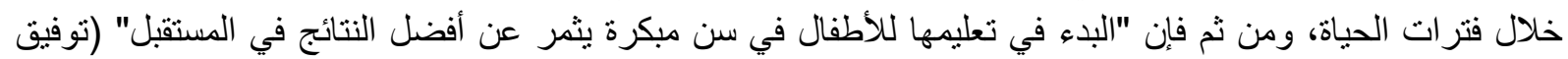

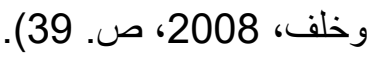

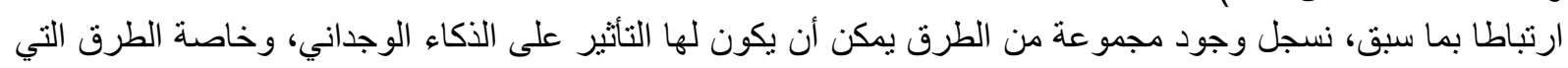

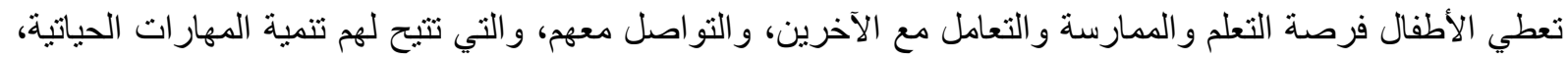

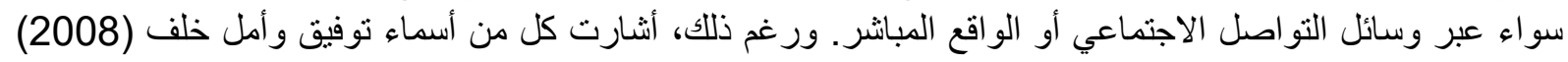

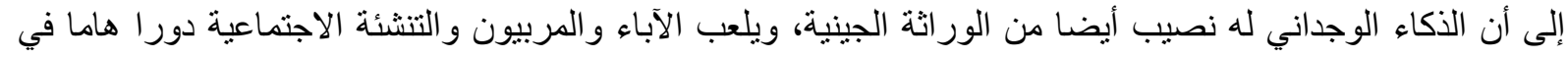
تتميته وتحقيق مستويات مرتفعة منه لأطفالهم، لكي تكون لهم قدرة كبيرة على التوا لتونق الفعال مع المو اقف الحياتية.

\section{7. الذكاء الوجداني والتوازن النفسي والاجتماعي}

ارتباطا بما ناقثناه في النقطة السالفة، فقد اختلفت آراء الباحثين حول التشميات التي أطلقت على مصطلح الذكاء

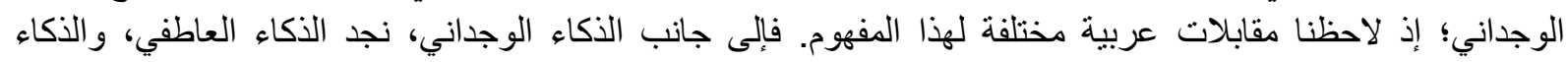

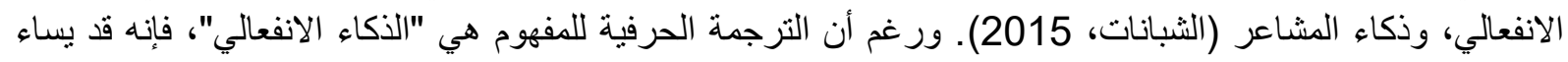

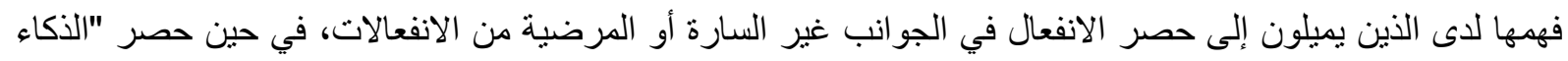

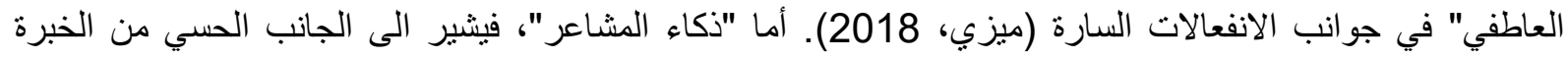

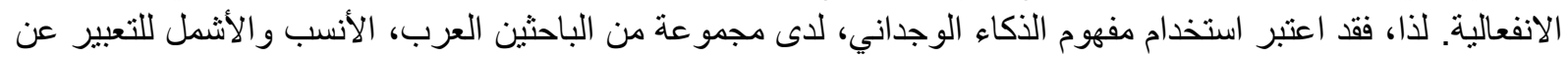

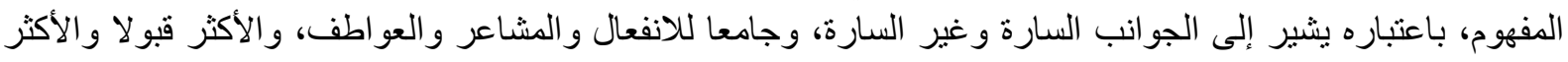

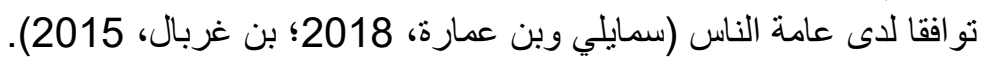

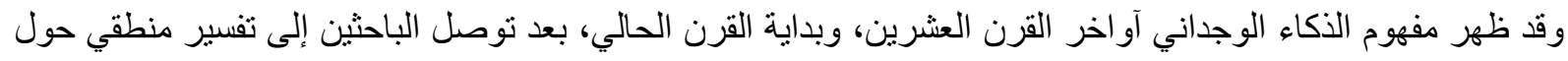

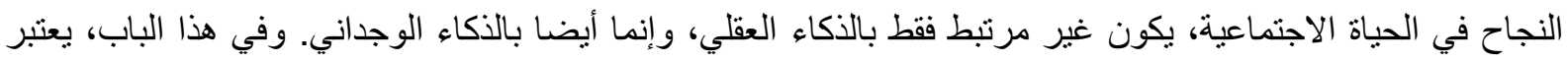
Pellitteri

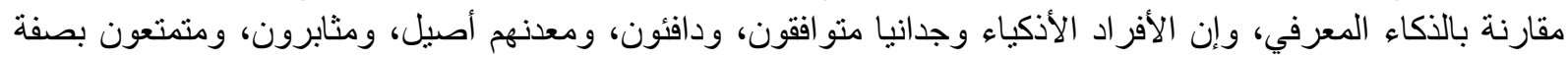

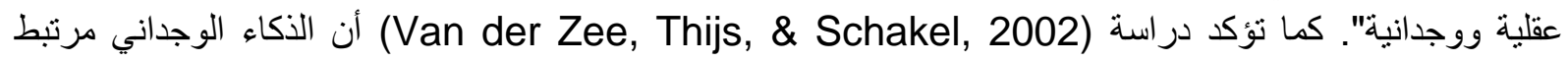

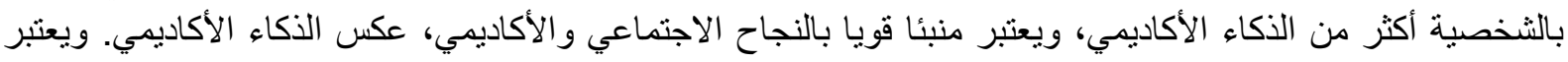

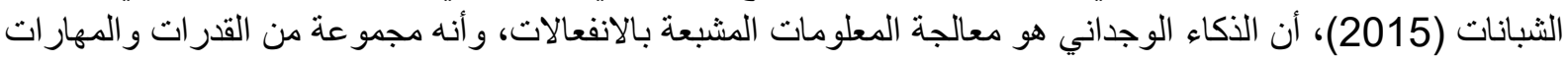

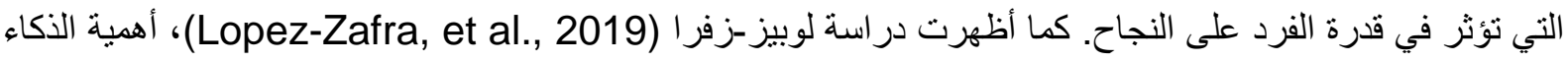
الوجداني في عملية التكيف الاجتماعي، وتطوير العلاقات الثخصية، وتبين أن المر اهقين الأكثر ذكاء عاطفيا، بستخمون التخين 
استر اتيجيات تكيفية أكثر فعالية، مما يخفق عليهم من تأثير الأحداث السلبية والمواقف الصعبة وغير المريحة، وتؤدي بهر

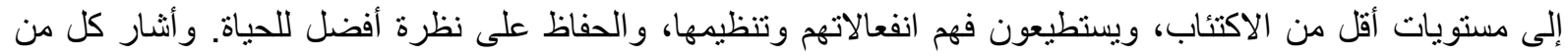

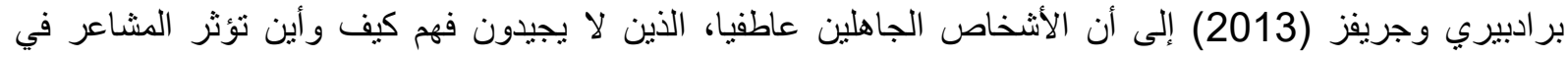

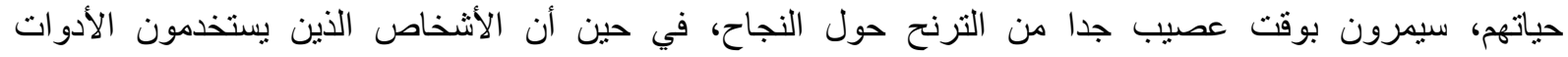

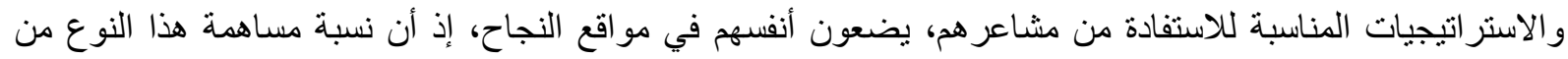

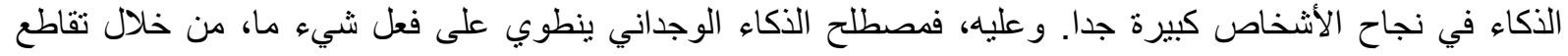

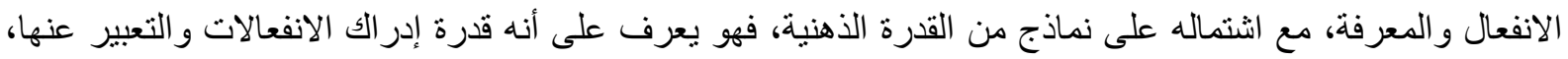

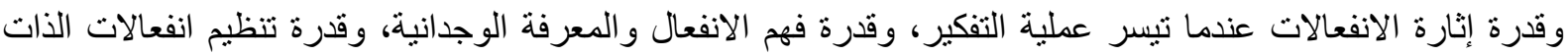

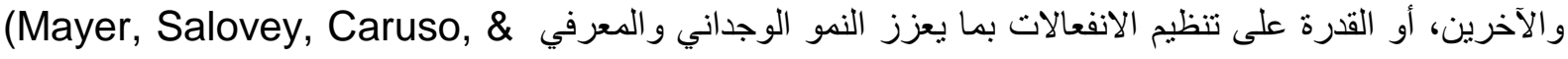
و Cherkasskiy, 2011; Kant \& Lenka, 2013)

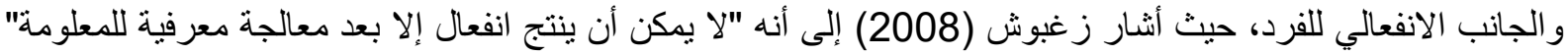

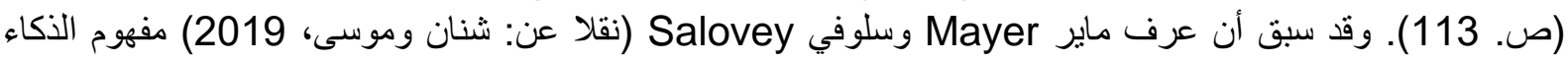

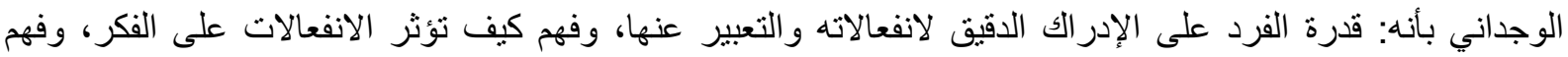

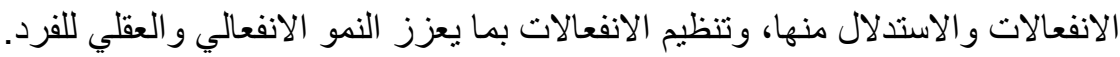

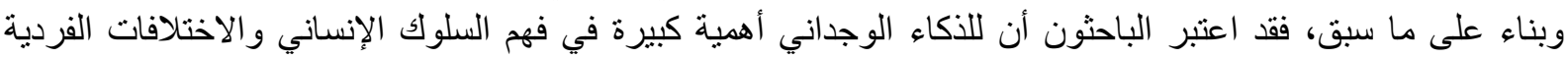

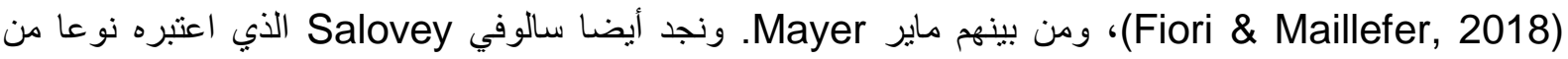

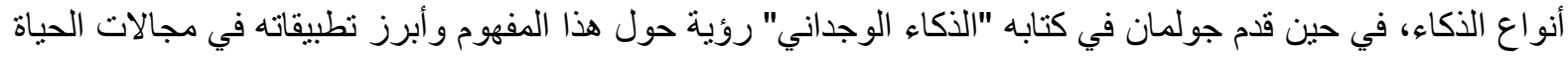

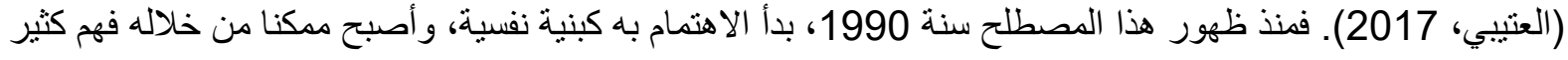

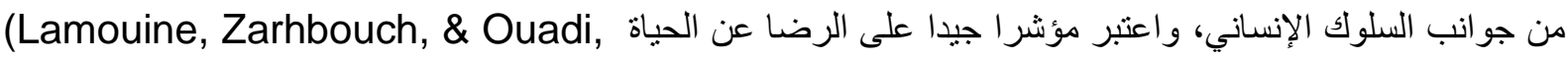

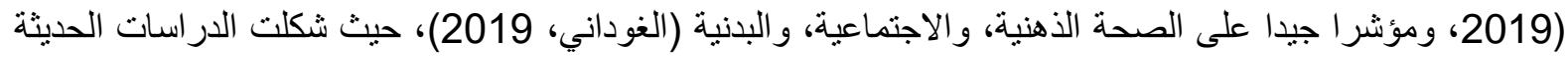

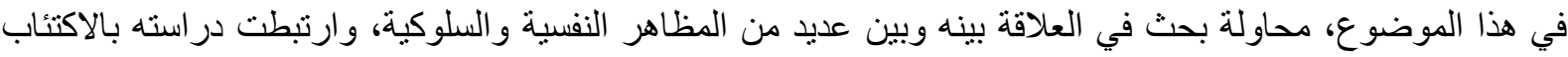

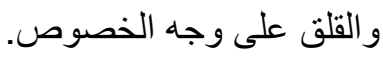

من خلال الطرح السالف، يتبين أن مفهوم الذكاء الوجداني قد أنثار نقاثنا كبيرا في مقاربته، مما جعل كلاً من ديفيز

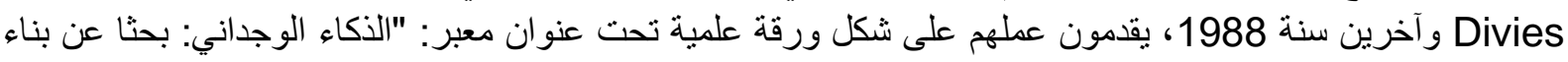

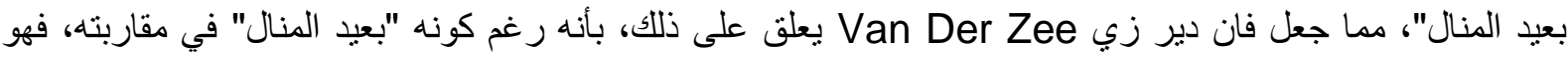

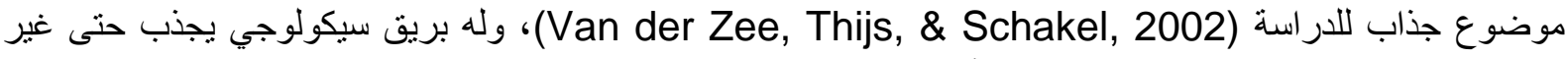

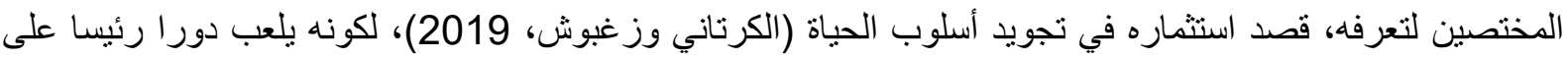

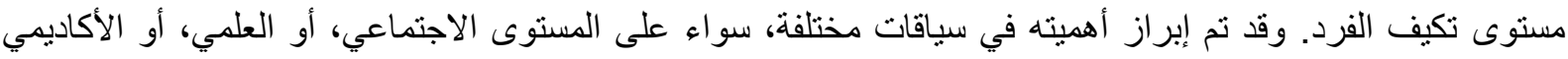

.(Lopez-Zafra, et al., 2019)

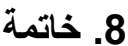

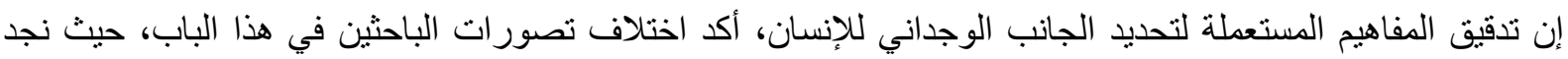

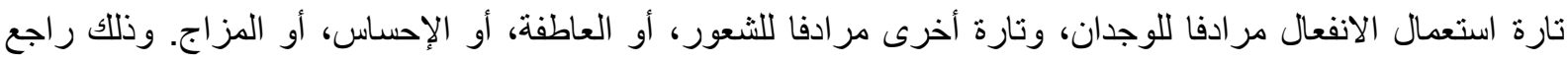

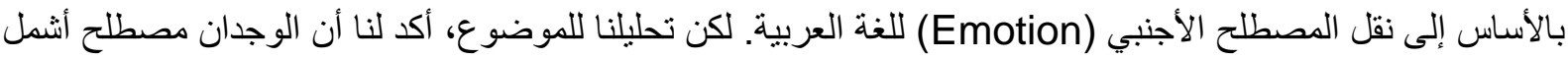

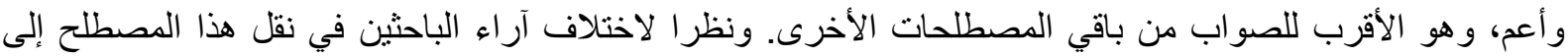

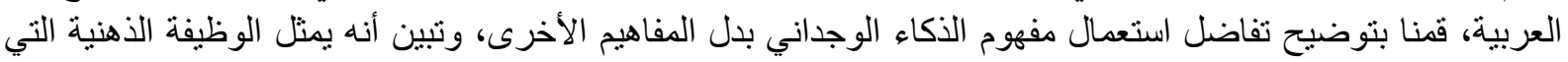

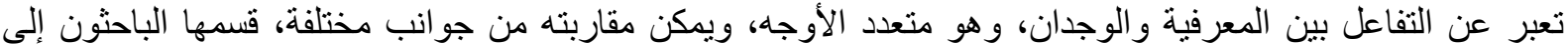

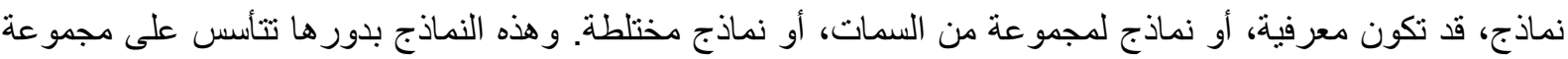

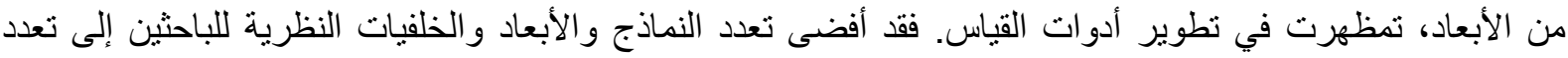

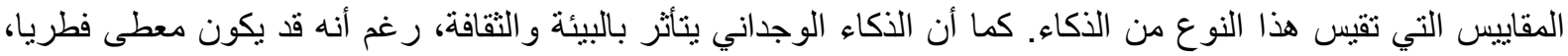

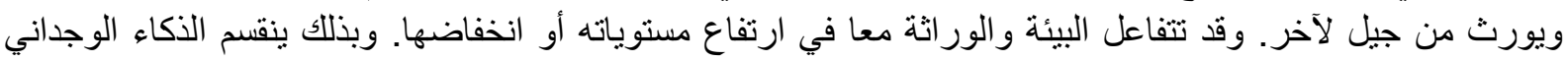

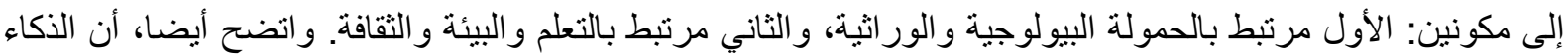

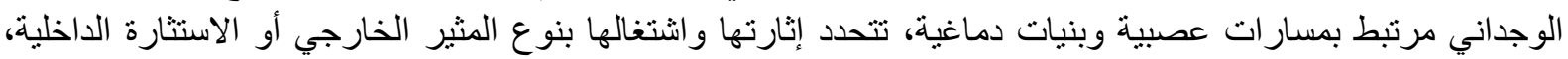

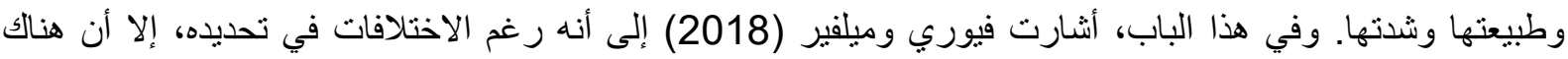


إجماع على أن الذكاء الوجداني متعدد الأوجه، ويمكن دراسته من زوايا مختلفة، مما أدى إلى انبثاق عدة نظريات ونماذج تفسيرية له.

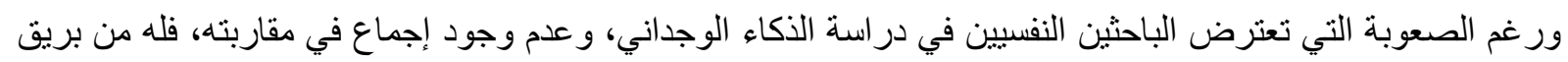

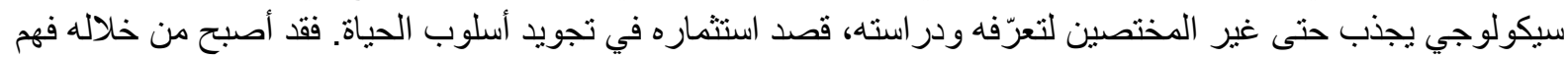

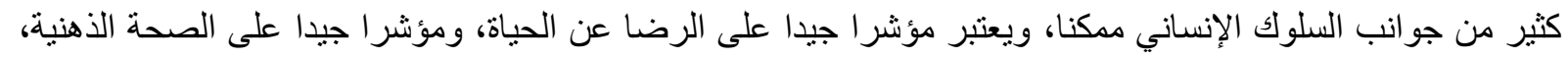

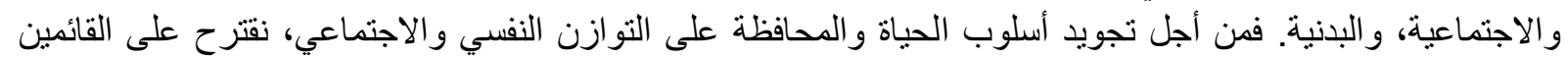

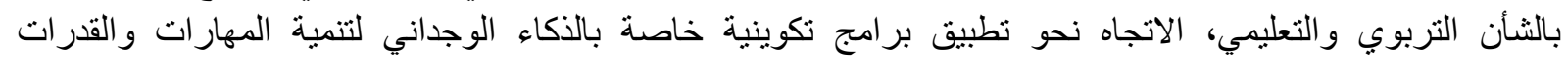

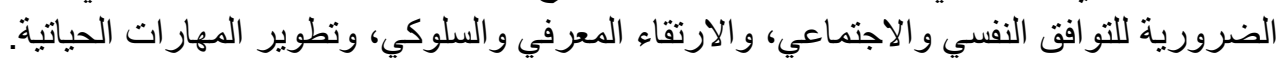

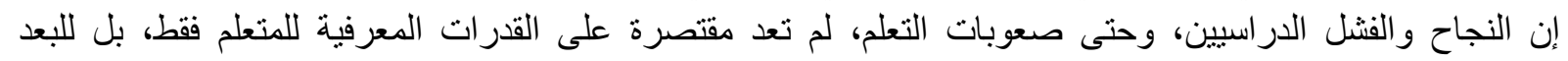

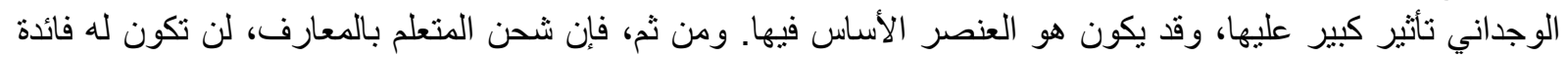

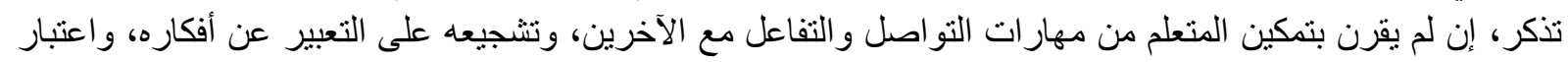

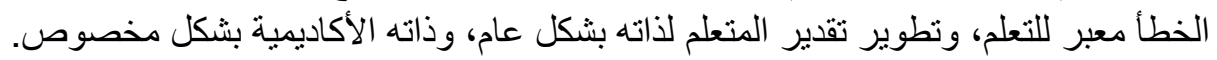

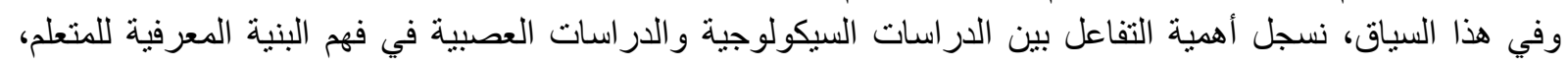

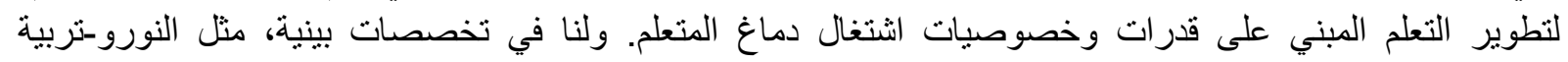

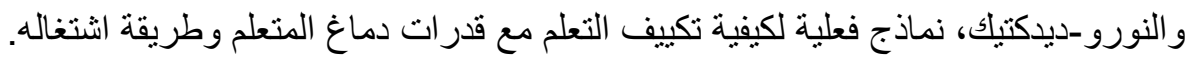

المصادر والمراجع

بر ادبيري، تر افيس، وجريفز، وجين (2013). الكتاب السريع للذكاء العاطفي (ط.1 ). (مكتبة جرير، مترجما) الرياض: مكتبة جرير.

بن غربال، سعيدة (2015). الذكاء العاطفي وعلاقته بالتوافق المهني. (مذكرة مقدمة لنيل شهادة الماجستير في العلوم

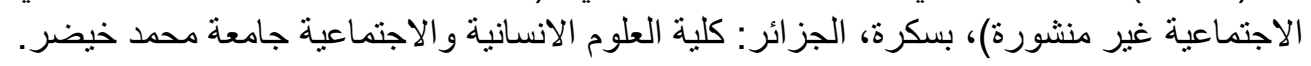

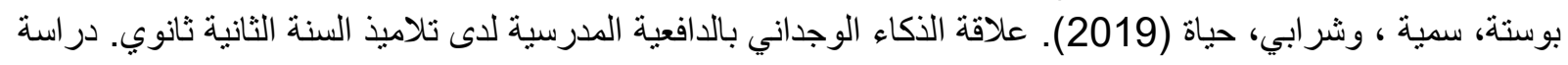

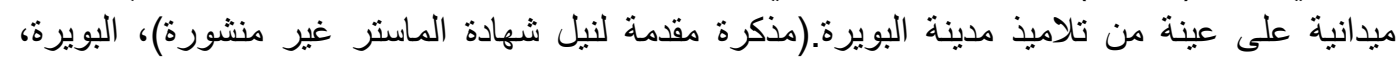

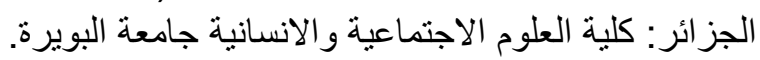

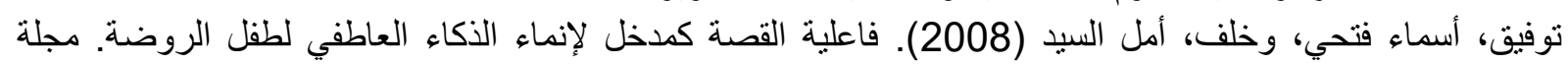

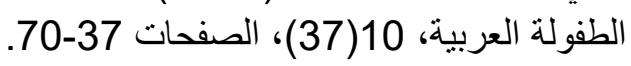

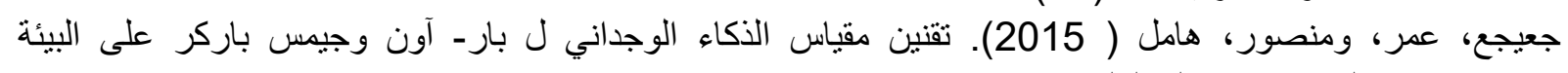

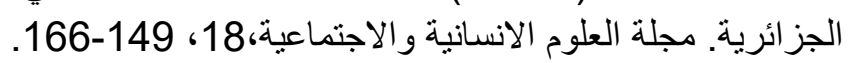

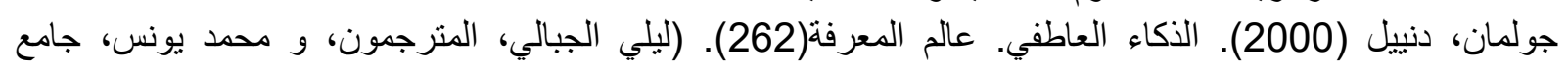

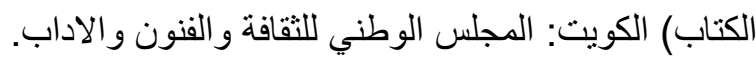

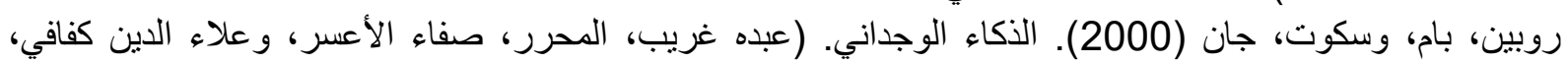

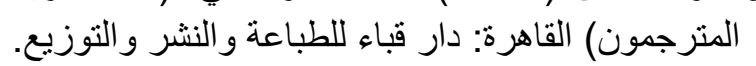

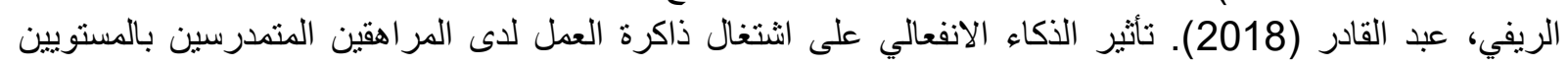

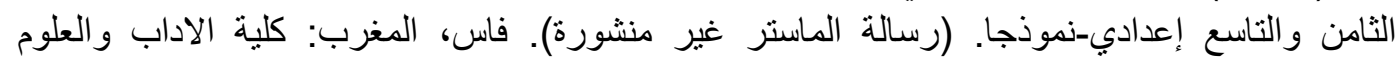

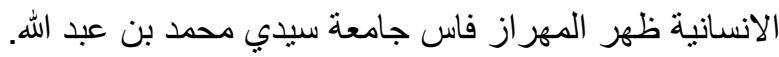

زغبوش، بنعيسى (2008). استراتيجة معالجة المعلومات في العلاج المعرفي. سيكولوجية الطفل: مقانية مقاربات معرفية

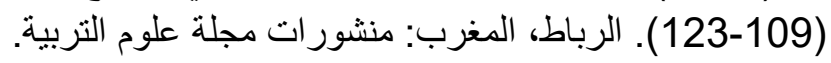

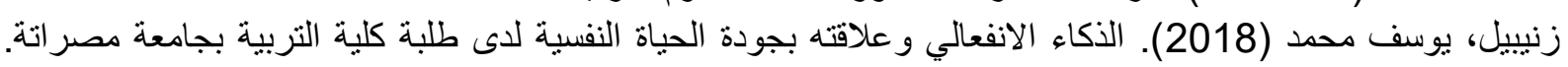

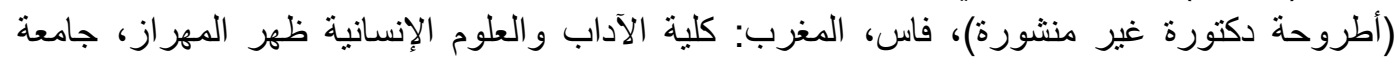
سيدي محمد بن عبد الله. سمايلي، محمود، وبن عمارة، سعيدة (2018). الذكاء الوجداني: مفهومه، نماذجه، وتطبيقاته في الوسط المدرسي. مجلة

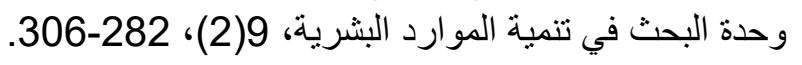


الثبانات، خالد بن عبد الله (2015). التحصيل الدراسي لدى الطلاب في ضوء النظرية الحديثة للذكاء دراسة وصفية

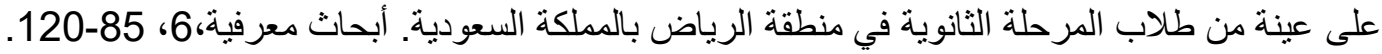

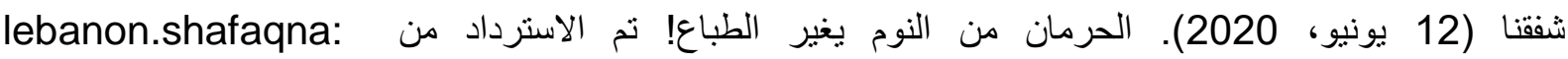
https://lebanon.shafaqna.com/news/35370

شنان، أ.، وموسى، م. (2019). الذكاء الوجداني وعلاقته بطول القامة ومحيط الر أس لدى تلاميذ مرحلة التعليم الأساسي

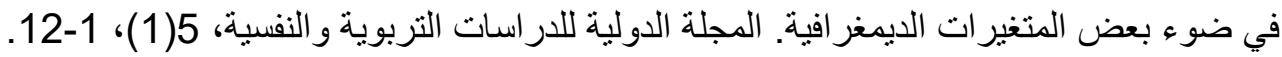

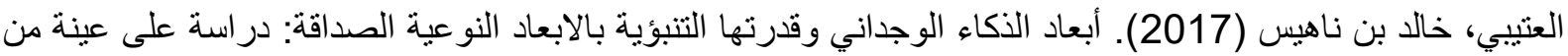

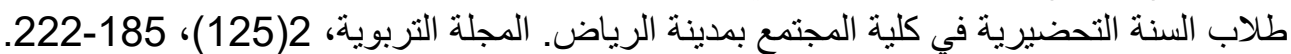

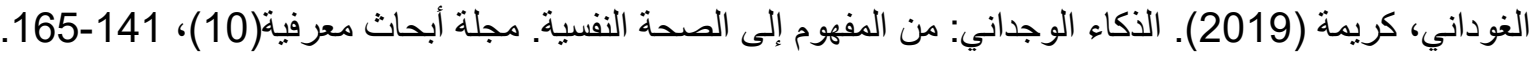

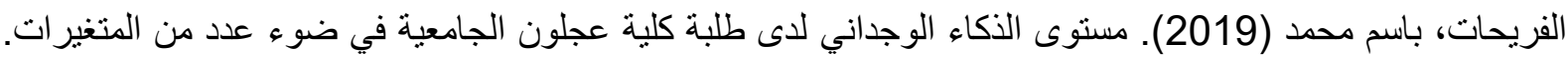

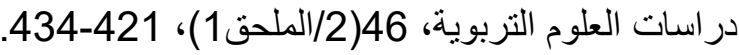

الكرتاني، وفاء، وزغبوش، بنعيسى (2019). الأسس سيكو-عصبية المعرفية للذكاء الوجداني. مجلة أبحاث

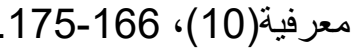

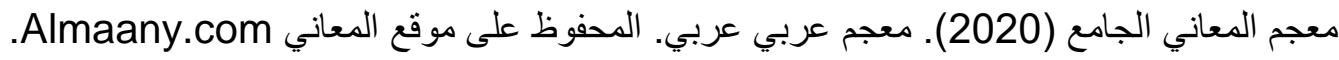

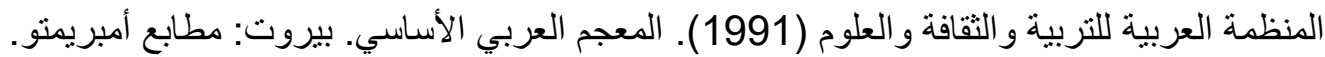

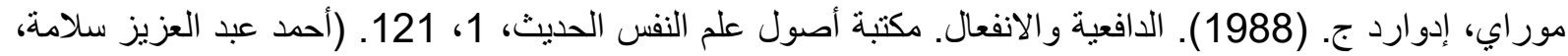

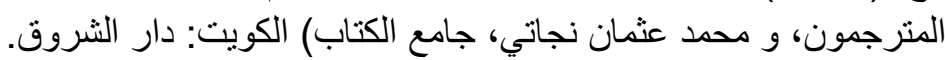

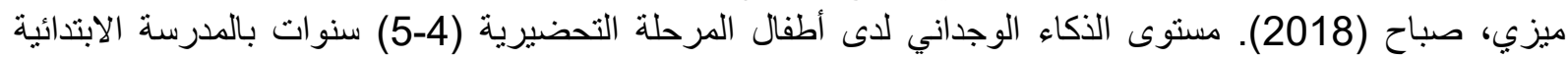

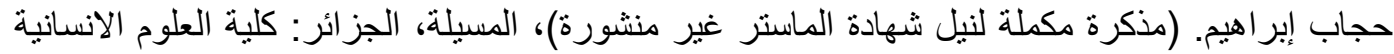

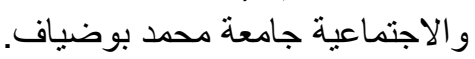

Badea, L., \& Panà, N. A. (2010). The Role Of Empathy In Developing The Leader's. Theoretical And Applied Economics, XVI( 2), 69-78.

Bar-On, R. (2006, Février). The Bar-On Model Of Emotional-Social Intelligence (ESI). Psicothema, 18Suppl, 13-25.

Briner, R. B., \& Totterdell, P. (2002). The Experience, Expression And Management Of Emotion At Work. In P. Warr (Ed.), Psychology At Work. (Fifth Ed., Pp. 229-252). Londan: Penguin Books.

El Ghoudani, K., Ramos-Álvarez, M. M., Lopezzafra, E., \& Pulido-Martos, M. (2021). Inteligencia Emocional. Modelo Habilidad: Escala De Inteligencia Emocional De Wong Y Law. Dans B. Zarhbouch, \& K. El Ghoudani, Escalas De Evaluación Psicológica: Adaptación Cultural $\mathrm{Y}$ Validation Psicométrica Al Ambito Educativo (Pp. 85-107). Fes: Publicaciones Del Laboratorio De Ciencias Cognitivas(9).

El Ghoudani, K., Ramos-Álvarez, M. M., Lopezzafra, E., \& Pulido-Martos, M. (2021). Inteligencia Emocional. Modelo Mixto: Escala Corta De Cociente Emocional De Bar-On. Dans \&. K. B. Zarhbouch, Escalas De Evaluación Psicológica: Adaptación Cultural $\mathrm{Y}$ Validation Psicométrica Al Ambito Educativo (Pp. 109-135). Fes: Publicaciones Del Laboratorio De Ciencias Cognitivas(9).

Ekkekakis, P. (2012). Affect, Mood,And Emotion. In G. Tenenbaum, R. C. Eklund, \& A. Kamata, Measurement In Sport And Exercise Psychology (Pp. 321332). United States Of America: Human Kinetics.

Fiori, M., \& Maillefer, A. V. (2018). Correction To: Emotional Intelligence As An Ability: Theory, Challenges, And New Directions. In K. Keefer, J. Parker, \& 
D. Saklofske (Eds.), Emotional Intelligence In Education (Pp. 23-47). Exceptionality The Springer Series On Human. Springer, Cham.Doi.Org/10.1007/978-3-319-90633-1_2.

Ioannidou, F., \& Konstantikaki, V. (2008). Empathy And Emotional Intelligence: What Is It Really About. International Journal Of Caring Sciences, 1(3), 118123.

Lamouine, M., Zarhbouch, B., \& Ouadi, K. (2019). L'intelligence Emotionnelle Et La Flexibilité Cognitive. International Conference On Human And Social Sciences Contemporary Issues (Pp. 129-141). Berlin: Democratic Arab Center For Strategic, Political \& Economic Studies.

Lopez-Zafra, E., Ramos-Álvarez, M. M., El Ghoudani, K., Luque- Reca, O., AugustoLanda, J. M., Zarhbouch, B., . . Pulido- Martos, M. (2019). Social Support And Emotional Intelligence As Protective Resources For Well-Being In Moroccan Adolescents. Front. Psychol, 10:1529. Doi: 10.3389/Fpsyg.2019.01529.

Mayer, J. D., Salovey, P., Caruso, D. R., \& Cherkasskiy, L. (2011). Emotional Intelligence. In R. J. Sternberg (Ed.), Kinds Of Intelligence (Pp. 528-549). New York : Cambridge University Press.

Terry, P. C., \& Lane, A. M. (2011). Mood And Emotions. The New Sport And Exercice Psychology Companion.

Van Der Zee, K., Thijs, M., \& Schakel, L. (2002). The Relationship Of Emotional Intelligence. European Journal Of Personality(16), 103-125.

Vijay, P., Bhatia, M., Sriniwas, J., \& Batra, D. (2011, OCTOBER). Emotions And Mood. Delhi Psychiatry Journal, 14(2), 202-228. 